\title{
Applying a stochastic-dynamic methodology (StDM) to facilitate ecological monitoring of running waters, using selected trophic and taxonomic metrics as state variables
}

\author{
Edna Cabecinha ${ }^{a, *}$, Pedro Silva-Santos ${ }^{a}$, Rui Cortes $^{b}$, João Alexandre Cabral ${ }^{a}$ \\ a Laboratory of Applied Ecology, CETAV-Department of Biological and Environmental Engineering, University of Trás-os-Montes e \\ Alto Douro, 5001-801 Vila Real, Portugal \\ b CEGE-Department of Forestry Engineering, University of Trás-os-Montes e Alto Douro, 5001-801 Vila Real, Portugal
}

\section{A R T I C L E I N F O}

\section{Article history:}

Received 8 March 2006

Received in revised form

12 April 2007

Accepted 18 April 2007

Published on line 30 May 2007

\section{Keywords:}

Aquatic ecosystem monitoring

Ecological indicators

Benthic macroinvertebrates

Biological metrics

Stochastic-dynamic methodology

\begin{abstract}
A B S T R A C T
As an improvement of a previous work [Cabecinha, E., Cortes, R., Cabral, J.A., 2004. Performance of a stochastic-dynamic modelling methodology for running waters ecological assessment. Ecol. Modell. 175, 303-317], the present paper examined the applicability of a holistic stochastic-dynamic methodology (StDM) in predicting the tendencies of benthic macroinvertebrate metrics from mountain streams facing expected scenarios either: (1) of pollution increase due to the agricultural intensification; or (2) of farming activity abandonment becoming less pollutant as a non-point source. The StDM is a sequential modelling process developed in order to predict the ecological status of changed ecosystems, from which management strategies can be designed. These procedures focus on the interactions between conceptually isolated key-components, such as some relevant trophic and taxonomic metrics and changes in local environmental conditions. The dataset recorded from the field included true gradients of environmental changes. The samples of aquatic macroinvertebrate, environmental and physical-chemical data were collected from four watersheds of mountain rivers in Northeast Portugal, between 1983 and 1985. The dynamic model developed was preceded by a conventional multivariate statistical procedure performed to discriminate the significant relationships between the selected components of the studied watersheds. The model validation was based on independent data from a watershed not included in the model construction. Overall, the simulation results are encouraging since they seem to demonstrate the StDM reliability in capturing the stochastic environmental dynamics of the studied aquatic ecosystems facing agricultural scenarios that will characterize the region, namely by predicting credible behavioural patterns for the selected metrics.
\end{abstract}

(c) 2007 Elsevier B.V. All rights reserved.

\section{Introduction}

For conservation and management purposes, the use of adequate ecological integrity indicators is particularly helpful in assessing the impact of environmental changes on characteristic ecological patterns (Barbour et al., 1999; Dolèdec et al., 1999; Rabeni, 2000; Andreasen et al., 2001; Dale and Beyeler, 2001; Karr and Rossano, 2001; Kurtz et al., 2001; Karr, 2002).

\footnotetext{
* Corresponding author. Tel.: +351 259350 238; fax: +351 259350266.

E-mail address: edna@utad.pt (E. Cabecinha). 
Ecological integrity is a concept centered in the system as a whole, but depends on the state of all components, such as the presence of species, autochthonous communities, and the maintenance of all the environmental conditions that support the ecosystem (Angermeier and Karr, 1994; Townsend and Riley, 1999; Dale and Beyeler, 2001). Since ecological indicators can reflect biological, chemical and physical aspects of ecological conditions, they have been used to characterize status, to track or predict changes, to identify stressors or stressed systems, to assess risk and to influence management actions (Seager, 1999; Rabeni, 2000; Karr and Chu, 2001; Kurtz et al., 2001; Karr, 2002).

In this paper, the feeding guilds and some relevant orders of the macroinvertebrate community were used as ecological integrity indicators of mountain running waters. These communities have been commonly chosen for aquatic bioassessment investigations as aquatic invertebrates respond rapidly to environmental changes and provide signs for the early detection of ecological changes (Barbour et al., 1999; Kimberling et al., 2001). Therefore, several studies have demonstrated the effectiveness of invertebrate bioassessment for detection of stream reaches impaired by a variety of point and non-point source pollutants (see Lenat, 1988; Thorne and Williams, 1997; Karr, 1999, 2002; Maxted et al., 2000; Whiles et al., 2000; Kurtz et al., 2001). In fact, the intolerant orders, like Ephemeroptera, Plecoptera and Trichoptera (EPT), are very sensitive to organic perturbations and they have the capacity for population recovery in response to good management procedures in previously disturbed ecosystems (Cortes, 1992; Barbour et al., 1999; Harris and Silveira, 1999; Karr, 2002).

The feeding guilds approach categorizes stream consumers into functional rather than taxonomic groups. Thus, rather than hundreds of consumers to be studied, there are a small number of groups of organisms which can be studied collectively from the perspective of their function in the stream ecosystem. This approach categorizes consumers based on their mechanisms for obtaining food and the particle sizes of the food obtained (Hershey and Lamberti, 1998). The major functional feeding groups are: (1) scrapers (grazers), which consume algae and associated material, (2) shredders, which consume leaf litter or other coarse particulate organic matter (CPOM-organic particles $>1 \mathrm{~mm}$ in diameter) including wood, (3) collector-gatherers, which collect fine particulate organic matter (FPOM-organic particles $<1 \mathrm{~mm}$ and $>0.45 \mu \mathrm{m}$ ) from the stream bottom, (4) collector-filterers, which collect FPOM from the water column using a variety of filtering devices, and (5) predators and parasites, which feed on other consumers (Hershey and Lamberti, 1998). Because each consumer species need not be studied individually to major components of organic matter processing, the functional feeding group approach greatly simplifies the study of stream ecosystems. It also provides a strong basis for comparative studies of streams, whereas it is much more difficult (and often less informative) to make such comparisons on a species by species basis (Hershey and Lamberti, 1998).

The most popular tools to evaluate the biological quality of streams, rivers, lakes and estuaries have been biological indexes, which reduce the dimensionality of complex ecological data sets to a single univariate statistic and ordination methods, which summarize the multi-dimensionality of eco- logical data sets in a 2D or 3D plots (Pardal et al., 2004). In ecological research, such tools have a scientific background and can be used as quantifiable measures. Nevertheless, ecological integrity assessment and community studies usually result in complex biological data sets. When applied to contexts relating to environmental management, namely in order to find ecological relevant holistic patterns and tendencies from such sets of data, it is necessary to reduce all the information to a summarized and simplified form.

The application of ecological models can synthesize the pieces of ecological knowledge, emphasizing the need for a holistic view of a certain environmental problem (Mitsch and Jørgensen, 1989). Although ecological models have been used to predict macroinvertebrate species responses to environmental stresses and habitat characteristics, most of them are static (e.g., Wright, 1995; Parsons and Norris, 1996; Kay et al., 1999; Marchant et al., 1999; Moss et al., 1999; Smith et al., 1999; Turak et al., 1999; Charvet et al., 2000; Oberdorf et al., 2001). When a time factor is present within the data, they are unable to estimate, in a comprehensible way, the structural changes when the habitat and environmental conditions are substantially changing (Jørgensen and Bernardi, 1997; Pardal et al., 2004). Therefore, ecological integrity studies have been improved by creating dynamic models that simultaneously attempt to capture the structure and the composition in systems affected by long-term environmental disturbances (Jørgensen and Bernardi, 1997; Ault et al., 1999; Brosse et al., 2001; Cabral et al., 2001; Costanza and Voinov, 2001; Jørgensen, 2001; Voinov et al., 2001; Santos and Cabral, 2003; Cabecinha et al., 2004; Silva-Santos et al., 2006; Karouby et al., 2007).

Moreover, in such applications, the rapid construction of predictive tools for ecological management, namely in terms of cost and speed of reliable assessment results, is crucial. In this scope, an expeditious stochastic dynamic methodology (StDM) has recently been developed and successfully applied in several types of ecological systems, such as mediterranean agro-ecosystems (Santos and Cabral, 2003; Cabral et al., 2007), mountain running waters (Cabecinha et al., 2004) and estuaries (Silva-Santos et al., 2006). Compared with traditional deterministic approaches, stochastic dynamic models have the advantage of taking into account random phenomena that characterize real systems (Van der Meer et al., 1996). The present paper proposes a conceptual approach for a future link between evaluations of the ecological status in running waters systems and a consistent mechanistic understanding of the holistic ecological processes, from which management strategies can be designed to restore ecosystems functions that have been damaged by human disturbances.

In a preliminary deterministic approach, we developed a model to validate simulations of the interactions between some relevant biological metrics (benthic macroinvertebrates) and physicochemical conditions in selected static scenarios (Cabecinha et al., 2004). Although these simulations are encouraging, we believe that our present proposal will provide the development of a true management tool, namely taking into account stochastic/random phenomena that characterize the real ecological processes (Van der Meer et al., 1996). Therefore, the main improvement is the stochastic background that makes possible the introduction of limits to credible environmental variation, such as the minimum and maximum 
values of recorded aquatic chemical variables (as suggested by Džeroski et al., 2000) and the seasonal random variation of the monthly accumulated precipitation over time. Since the mountain running waters are characterized by a high degree of heterogeneity in space and time, influenced by many interacting factors and by feedback mechanisms, the StDM is particularly helpful to capture these multi-factor influences in natural stochastic scenarios.

The objectives were to validate and demonstrate the applicability of a holistic StDM approach in the scope of the running waters monitoring and management, by focusing on the interactions between conceptually isolated key-components in such systems, namely between some relevant trophic and taxonomic metrics and physicochemical conditions. The hypotheses to be tested include: (1) that the selected metrics are representative of the local macroinvertebrate community that changes in some predictable way with the increasing of human and natural influences, and (2) that the ecosystem integrity can be assessed by the state variables, assumed as important ecological indicators, used in the dynamic model construction. These hypotheses were tested by applications of a StDM model in order to capture, by simple, suitable and intuitive outputs, the stochastic complexity of some ecological trends resulting from the gradients of changes expected in the studied aquatic ecosystems.

\section{Methods}

\subsection{Study area}

The study was carried out in four main streams from the Douro river watershed, located in Northeast Portugal: the Olo $(\mathrm{O})$,
Corgo (C), Pinhão (P) and Tinhela (T) rivers (Fig. 1). The watersheds of these rivers have different lithological, topographical, hydrological and land use features. The studied streams range from 2 nd to 10 th in order of altitude $(50-1500 \mathrm{~m})$. The precipitation pattern, sources of disturbance and main land uses of the region are described in Cabecinha et al. (2004).

\subsection{Field program}

The environmental and biological data used to support the model construction was collected in 17 sampling stations from three watersheds (O, C and T, Fig. 1) (Cortes, 1992), representative of the typological variations in the studied region. The model was validated with independent data from three sampling stations (P1, P2 and P3) located in the Pinhão watershed (Fig. 1). Sampling was carried out from March 1983 to November 1985. Four sampling campaigns were made annually, corresponding to Spring, Summer, Autumn and Winter periods (see Cortes, 1992 for details). In each campaign, semi-quantitative biological samples were taken monthly in all sampling stations. Therefore, the recorded data allowed incorporating into the model the seasonality of the natural variations that occurred in these aquatic systems. Aquatic macroinvertebrates were identified at species level and grouped in relevant trophic and taxonomic metrics as they reveal high sensitivity to environmental stress (Cortes, 1992; Barbour et al., 1999; Karr, 1999; Charvet et al., 2000; Maxted et al., 2000; Doisy and Rabeni, 2001; Cortes et al., 2002). The specifications of all physicochemical and biological variables considered in this study are presented in Table 1.

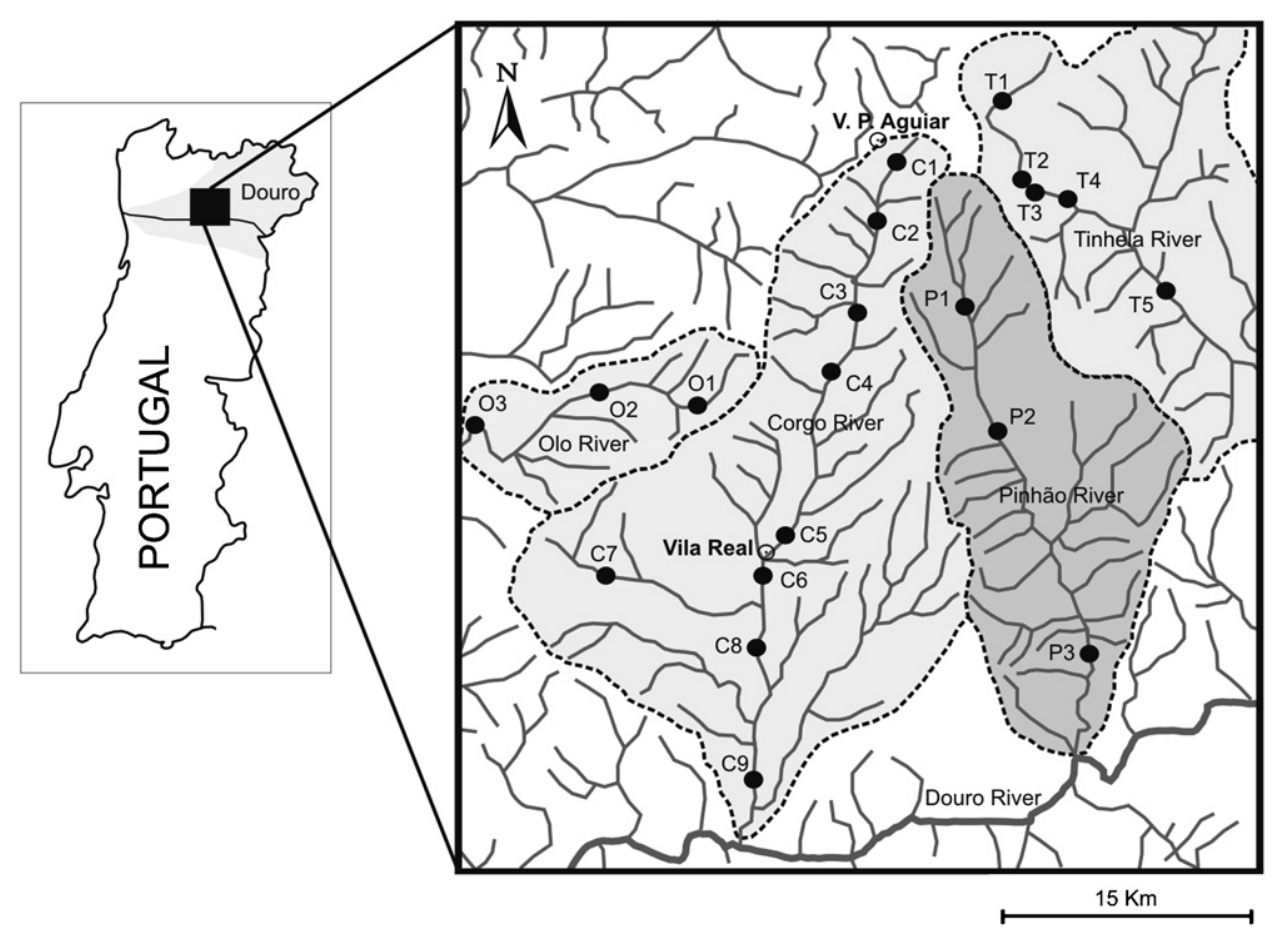

Fig. 1 - Location of the study area in Northeast Portugal (shaded area) with the different watersheds used in the construction of the model (Olo $(\mathrm{O})$, Corgo $(\mathrm{C})$ and Tinhela $(\mathrm{T})$ rivers) and in the respective validation (Pinhão river (P)). 
Table 1 - Specification (units and taxa resolution) of all physicochemical and biological variables considered in this study (IN and OUT represent, respectively, the surviving independent variables (used in the dynamic model construction) and the removed independent variables by a previous step down multiple regression analysis)

\begin{tabular}{|c|c|c|}
\hline Variables & Specification & Code \\
\hline $\begin{array}{l}\text { Independent variables IN } \\
\text { Alkalinity } \\
\text { Altitude of the site } \\
\text { Biochemical oxygen demand } \\
\text { Distance from the stream source } \\
\text { Nitrates-N } \\
\text { Oxygen content } \\
\text { pH } \\
\text { Precipitation } \\
\text { Temperature }\end{array}$ & $\begin{array}{l}\text { meq } \mathrm{L}^{-1} \\
\mathrm{~m} \\
\mathrm{mgL}^{-1} \\
\mathrm{Km}^{-1} \\
\mathrm{mgL}^{-1} \\
\mathrm{mgL}^{-1} \\
\mathrm{pH} \text { units } \\
\mathrm{mm} \\
{ }^{\circ} \mathrm{C}\end{array}$ & $\begin{array}{l}\text { ALK } \\
\text { ALT } \\
\text { BOD }_{5} \\
\text { DSOURCE } \\
\mathrm{NO}_{3} \\
\mathrm{O}_{2} \\
\mathrm{pH} \\
\text { PREC } \\
\text { TEMP }\end{array}$ \\
\hline $\begin{array}{l}\text { Independent variables OUT } \\
\text { Chemical oxygen demand } \\
\text { Chlorides } \\
\text { Conductivity at } 20^{\circ} \mathrm{C} \\
\text { Hardness }\end{array}$ & $\begin{array}{l}\mathrm{mgL}^{-1} \\
\text { meq L }^{-1} \\
\mu \mathrm{mhos} \mathrm{cm}^{-1} \\
\text { meq L }\end{array}$ & $\begin{array}{l}\text { COD } \\
\text { CL } \\
\text { COND } \\
\text { HARD }\end{array}$ \\
\hline $\begin{array}{l}\text { Ecological indicators } \\
\text { Taxonomic metrics } \\
\text { Number of Ephemeroptera taxa } \\
\text { Number of Plecoptera taxa } \\
\text { Number of Tricoptera taxa } \\
\text { Number of EPT taxa }\end{array}$ & $\begin{array}{l}\text { No. of species } \\
\text { No. of species } \\
\text { No. of species } \\
\text { EPT + PLEC + TRIC }\end{array}$ & $\begin{array}{l}\text { EPH } \\
\text { PLEC } \\
\text { TRIC } \\
\text { EPT }\end{array}$ \\
\hline $\begin{array}{l}\text { Trophic metrics } \\
\text { Number of Gatherers and Filterers taxa } \\
\text { Number of Predators and Parasites taxa } \\
\text { Number of Scrapers taxa } \\
\text { Number of Shredders taxa }\end{array}$ & $\begin{array}{l}\text { No. of species } \\
\text { No. of species } \\
\text { No. of species } \\
\text { No. of species }\end{array}$ & $\begin{array}{l}\text { GTH and FILT } \\
\text { PRD and PRS } \\
\text { SRCP } \\
\text { SHRD }\end{array}$ \\
\hline
\end{tabular}

\subsection{Data analysis}

The StDM model proposed is preceded by a conventional multivariate statistical procedure. A stepwise multiple regression analysis (Zar, 1996) was used to test relationships between the biological metrics and the environmental variables. The dependent variables correspond to the selected metrics expressed, in number of species. The independent variables were the environmental parameters displayed in Table 1. A step down procedure was used so that the effect of each variable in the presence of all others could be examined first, with the least significant variable being removed at every step. The analysis stopped when all the remaining variables had a significance level $P<0.05$ (Zar, 1996). Although the lack of normal distribution of the dependent variables was not solved by any transformation (Kolmogorov-Smirnov test), the linearity and the homoscedasticity of the residuals were achieved by using logarithmic transformations $\left(X^{\prime}=\log [X+1]\right)$ in each side of the equation, i.e., on both dependent and independent variables (Zar, 1996). The lack of substantial intercorrelation among independent variables was confirmed by the inspection of the respective tolerance values. All the statistical analysis was carried out using the software SYSTAT $8.0^{\circledR}$.

Since the previous statistical procedures are static, the initial data set included true gradients of environmental characteristics and man-induced disturbances. In this way, the factors of time and space were implicit in the respective treatment and the significant partial regression coefficients were assumed as relevant holistic ecological parameters in the dynamic model construction. This model does not distinguish between different species within the selected metrics, but considers them as a whole in each corresponding state variable. Therefore, in a holistic perspective, the partial regression coefficients represent the global influence of the habitat variables selected that are of significant importance on several complex ecological processes. Yet, the latter were not included explicitly in the model, but were related to the selected trophic and taxonomic metrics. This is the heart of the philosophy of the StDM. For the development of this model the software STELLA 8.1.1 ${ }^{\circledR}$ was used.

For validation purposes, independent biological and physicochemical data from the three sampling stations of the Pinhão watershed (P1, P2 and P3) were used to confront the simulated values of a given metric, resulting from the introduction of the respective real physicochemical data into the model, with the real values of the same metric contemporaneous to those environmental parameters. A regression analysis (MODEL II) was performed to compare the observed real values of the selected ecological metrics with the expected values obtained by model simulations for the same periods. At the end of each analysis, the $95 \%$ confidence limits for the intercept and the slope of the regression line were determined, which, together with the results of the respective analysis of variance (ANOVA), allowed us to assess the proximity of the simulations produced with the observed values (Sokal and 
Rohlf, 1995). When the results of the regression analysis were statistically significant, i.e., when the intercept of the regression line was not statistically different from 0 and the slope was not statistically different from 1 , the model simulations were considered validated (Sokal and Rohlf, 1995; Oberdorf et al., 2001).

For assessment comparisons, we must be able to identify the ecological properties that are expected to occur in the absence of significant human alterations (pristine condition) or attainable if human disturbance ceases. Since we had no knowledge about the biota that existed at the studied sites prior to human alteration, we took the environmental data reported in the eighties as a reference situation. In fact, in that period, the studied watersheds presented, in general, good water quality (clean waters, not polluted or little altered), according to the BMWP' (Alba-Tercedor and Sánchez-Ortega, 1998) and IBB (Pauw and Vanhooren, 1983) indexes. Therefore, a reference table was constructed in order to hold the ecological characteristics of a "typical" mountain stream of northeast Portugal. A theoretical data watershed division, regarding altitudinal gradients, was adopted based in the Water Framework Directive 2000/60/EC and its upcoming monitoring program of the ecological status for surface waters. Three altitude classes are considered: (a) high altitude $(>800 \mathrm{~m})$, (b) mid altitude $(200-800 \mathrm{~m})$ and $(\mathrm{c})$ lowland $(<200 \mathrm{~m})$. The average and standard deviation of environmental variables from the studied watersheds were calculated for each of these three altitude classes and were used to discriminate the maximum and minimum values of each environmental variable, included in the model as a RANDOM function. Thus, the model is prepared to work with table functions for validation purposes (Validation Mode) and to produce stochastic simulations based on the monthly random variability of each environmental variable (Random Mode). The selection of the model working mode is done by switching the toggle option between 0 and 1 for validation or stochastic calculations, respectively.

The stochastic scenario considered, for academic demonstration purposes, was based on a possible temporal succession of farmland activities vs. land abandonment in the study region. Since physical chemical variables were monitored in the station C6, approximately 10 years later from the data used for the model construction, we used such information to represent a potential water quality degradation in C6 (Sampaio, 1995). In fact, according to Sampaio (1995), this sam- pling station displayed a typical diagnosis of eutrophication. Thereafter, nitrate concentrations were compared seasonally between 1984 (Cortes, 1992) and 1994 datasets (Sampaio, 1995 ) in order to calculate the respective increasing rate. We assumed the slope of the regression line between nitrate concentrations and time (in months) as a temporal rate for such perturbation. The following two steps of agricultural pattern changes were adopted through a simulation period of 22 years, using the station C6 as example: (1) the progressive nitrate increasing rates, included into the model as a RAMP function, occurs in the first 12 years due to the agricultural intensification, and (2) the abandonment of the farming activity, which allow a gradual water quality recovery, is simulated during the last 10 years. The stochastic simulations were determined by RANDOM functions, with a monthly variation, taking into account the standard deviations limits for each environmental variable considered. For graphical representations, 10 stochastic simulations were carried out for the simulation period and the average tendencies were calculated for nitrate concentrations and for the sensitive taxonomic metric EPT (Ephemeroptera + Plecoptera + Trichoptera) (Cortes, 1992; Barbour et al., 1999; Harris and Silveira, 1999; Karr, 2002).

\section{Results}

\subsection{Effects of environmental factors in biological metrics}

A stepwise multiple-regression analysis was used to search for significant correlations between the selected trophic and taxonomic metrics and the mixed environmental variables of the three watersheds used in the model construction. From the 13 environmental variables considered, five were excluded from the model $(P>0.05)$, namely chemical oxygen demand, chlorides, conductivity, hardness, and phosphates-P. The environmental variables associated with a degradation gradient seemed to be the main influencing factors on metrics related to the macroinvertebrates more sensitive to organic pollution. In fact, the increase of nitrate concentrations, an indicator of potential organic perturbation, seemed to affect negatively the number of species of Ephemeroptera (EPH), Trichoptera (TRIC), collectors gatherers and filterers (GTH and FILT), predators and

Table 2 - The regression equations, degrees of freedom (d.f.), coefficient of determination $\left(R^{2}\right)$, F-values and their significance level $(" P<0.05 ; " P<0.01 ; " P<0.001)$ for all the variables combination selected as significant by stepwise multiple regression

\begin{tabular}{|c|c|c|c|}
\hline Equations & d.f. & $R^{2}$ & F \\
\hline $\log \mathrm{EPH}=1.805+0.255(\log \mathrm{DSOURCE})-1.718(\log \mathrm{pH})-0.831\left(\log \mathrm{NO}_{3}\right)$ & 68 & 0.263 & $6.637^{* * *}$ \\
\hline $\log$ PLEC $=-1.385+0.145(\log$ PREC $)+0.457(\log$ ALT $)+0.256(\log$ DSOURCE $)$ & 68 & 0.504 & $19.333^{* * *}$ \\
\hline $\log$ TRIC $=-0.300+0.305\left(\log \mathrm{BOD}_{5}\right)+0.274(\log \mathrm{ALT})-0.822\left(\log \mathrm{NO}_{3}\right)$ & 68 & 0.253 & $6.238^{* * *}$ \\
\hline $\log \mathrm{GTH}$ and FILT $=0.783+0.317\left(\log \mathrm{BDO}_{5}\right)-0.774\left(\log \mathrm{NO}_{3}\right)$ & 69 & 0.257 & $5.488^{* *}$ \\
\hline $\log P R D$ and $P R S=2.042+1.469(\log A L K)-1.528(\log \mathrm{pH})-0.862\left(\log \mathrm{NO}_{3}\right)$ & 68 & 0.205 & $5.835^{* *}$ \\
\hline $\log \mathrm{SRCP}=-0.744+0.147(\log \mathrm{PREC})+0.256(\log \mathrm{ALT})+0.266(\log$ DSOURCE $)$ & 68 & 0.138 & $3.622^{*}$ \\
\hline $\log \mathrm{SHRD}=-1.978+0.950\left(\log \mathrm{O}_{2}\right)+1.359(\log \mathrm{ALK})+0.526(\log \mathrm{ALT})$ & 68 & 0.515 & $15.925^{* * *}$ \\
\hline
\end{tabular}


parasites (PRD and PRS). All the remaining physicochemical significant influences are expressed in Table 2.

\subsection{Model conceptualization and equations}

The diagram of the model presented in Fig. 2 is based on the relationships detected in multiple regression analysis (Table 2) and on existing relevant regional data sets (Cortes, 1992). Therefore, the model includes seven state variables, corresponding to the trophic and taxonomic metrics selected (Fig. 2). Difference equations that describe the processes affecting the state variables are expressed in a logarithm of the respective biological metrics (Fig. 2 and Appendix A, Difference equations). The initial values of all state variables, indicated in Appendix A (Process equations), were assumed to be zero, given the lack of knowledge of the initial situation in t0. Later, for validation purposes, the initial value was discarded, since only in t1 (first month of the simulation) was it possible to take into account the influences of the environmental variables, whose seasonal fluctuations were introduced into the model as table functions (Appendix A, Table functions). Although table functions have an apparent discrepancy among the number of values and the time units, this evidence results from a premeditated operation in order to get a contemporaneity (i.e., in the same $\mathrm{dt}$ ) between the influence of the physical-chemical parameters and the reaction of the potentially affected metrics. In fact, the difference equations did not allow these simultaneous simulations. In our case, this is crucial for validation purposes since the real independent biological and physicochemical data used to confront the simulated values of a given metric (resulting from the introduction of the respective real physicochemical data into the model) with the real values of the same metric, were contemporaneous, i.e., were collected in the same month. With this adjustment in table functions, it was possible to perform a regression analysis (MODEL II) in order to compare the observed real values of the selected ecological metrics with the expected values obtained by model simulations for the same periods.

The inflows affecting the state variables, Ephemeroptera (EPH gains), Plecoptera (PLEC gains), Trichoptera (TRIC gains), Gatherers and Filterers (GTH and FILT gains), Predators and Parasites (PRD and PRS gains), Scrapers (SRCP gains) and Shredders (SHRD gains), were based on the positive constants and all positive partial coefficients of each metric resulting from the previous multiple regression analysis (Fig. 2, Table 2 and Appendix A, Difference and Process equations). However, all metrics were affected by an outflow (EPH losses, PLEC losses, TRIC losses, GTH and FILT losses, PRD and PRS losses, SRCP losses, SHRD losses) related to the negative constants and partial regression coefficients (Fig. 2, Table 2 and Appendix A, Difference and Process equations). Although the output for each metric in our stochastic dynamic model simulation is composed of a given value per time unit, the respective state variable may result in a cumulative behaviour over time in response to environmental condition changes. Therefore, to prevent this from happening, seven outflow adjustments were incorporated into the model (EPH adjust, PLEC adjust, TRIC adjust, GTH and FILT adjust, PRD and PRS adjust, SRCP adjust, SHRD adjust). These outflow adjustments aim to empty the ecological metric state variables at each time step, by a "flushing cistern mechanism", before beginning the next step with new environmental influences (Fig. 2 and Appendix A, Difference and Process equations). For process compatibilities and a more realistic comprehension of the model simulations, some conversions were introduced, denominated as associated variables (Fig. 2 and Appendix A, Associated variables). Regarding the trophic and taxonomic metrics, these conversions were obtained through an inverse transformation (anti-logarithmic), which transforms logarithms into feeding measures expressed in the original measurement units (EPH, PLEC, TRIC, GTH and FILT, PRD and PRS, SRCP, SHRD). The physicochemical variables were logarithm transformed for a compatible integration into the balance of the state variables (Fig. 2 and Appendix A, Associated variables). This transformation was incorporated because the data required for the state variables balances should use the same units to obtain the significant partial regression coefficients, assumed to be holistic ecological parameters (see Methods). Therefore, only logarithms of the physicochemical variables are acceptable in the inflows and outflows of the state variables (Fig. 2 and Appendix A, Difference and Process equations). Thus, the model is prepared to accept and transform real data from the habitat variables and to convert logarithmic outputs from a specific state variable simulation back into the original units. Some environmental and programming values, such as distance from the stream source (DSOURCE), Stochastic ON OFF and perturbation option, were static and, therefore, were introduced in the model as constants (Appendix A, Constants). The number of species of EPT, a composed variable resulting from the sum of the variables EPH, PLEC and TRIC, was used to complete the output of the model (Fig. 2 and Appendix A, Composed variables). Programming functions, such as perturbation rate and stochastic calculations of the environmental variables along time, were introduced in the model as RAMP and RANDOM functions, respectively (Figs. 2 and 3; Appendix A, Other functions). The influence of the environmental data was controlled by switching the two operating modes (Appendix A, Constants): as table functions for validation purposes (Appendix A, Table functions) and as monthly stochastic calculations, using RANDOM functions (Fig. 3 and Appendix A, Other functions), incorporating the natural stochastic fluctuations that characterizes this kind of variables.

\subsection{Model simulations}

The temporal unit chosen was the month, because it captures in an acceptable way the average ecological variations that occur in lotic systems. Differential equations were numerically integrated using Euler's integration method. For precipitation values, we considered the data from a typical year that would correspond to the averages calculated over a period of 30 years (1961-1990). In this work, all the performed simulations have a total length of 12 months, beginning in the spring, coinciding with the first sampling campaign carried out by Cortes (1992).

For the relevant trophic metrics adopted, the model successfully predicts the behaviour of the biological metrics under the influence of independent environmental variables 


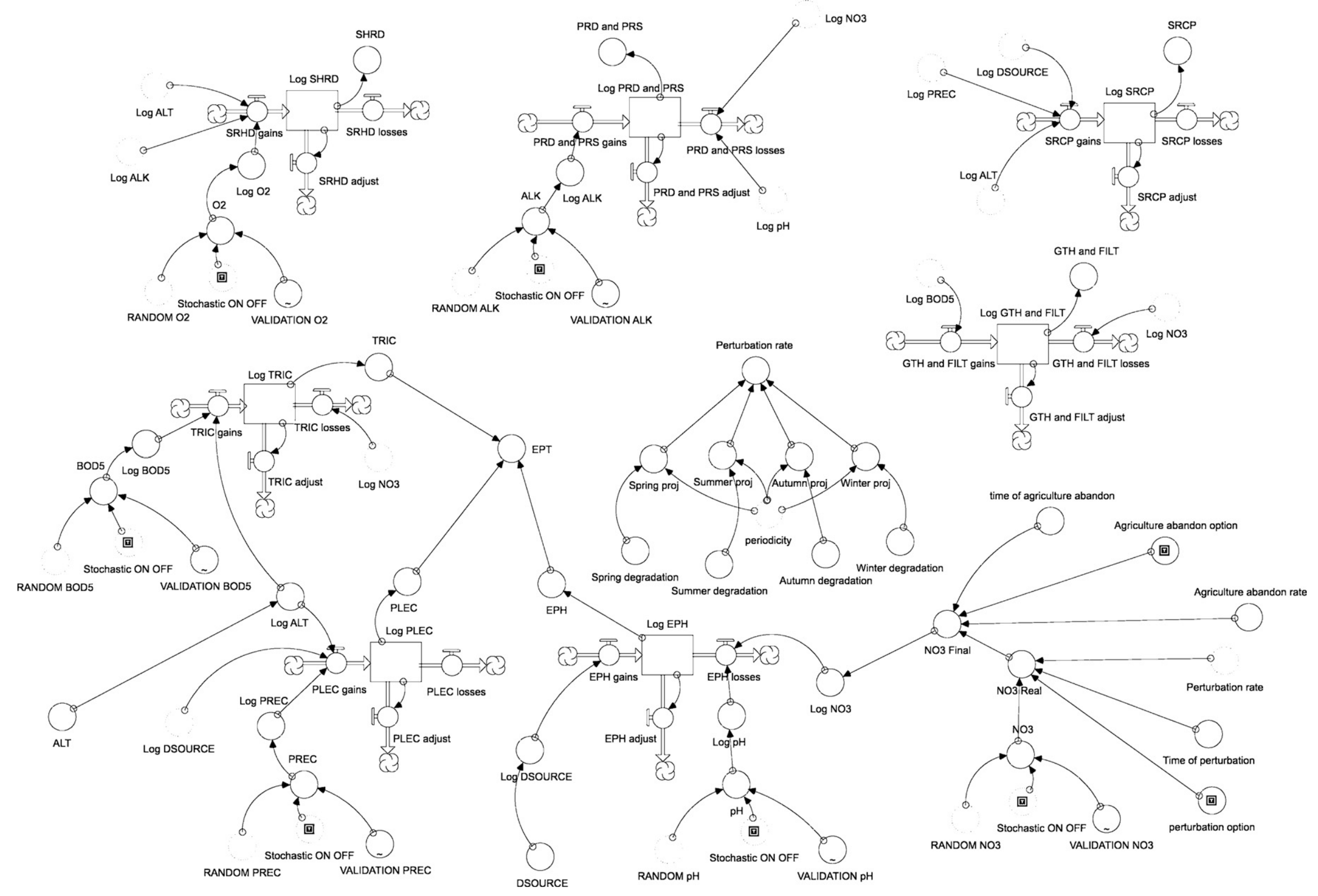

Fig. 2 - Conceptual diagram of the sub-model used to predict trophic and taxonomic metrics by given environmental variables from the studied watersheds in Northeast Portugal. The specification of all variable codes is expressed in Table 1. 

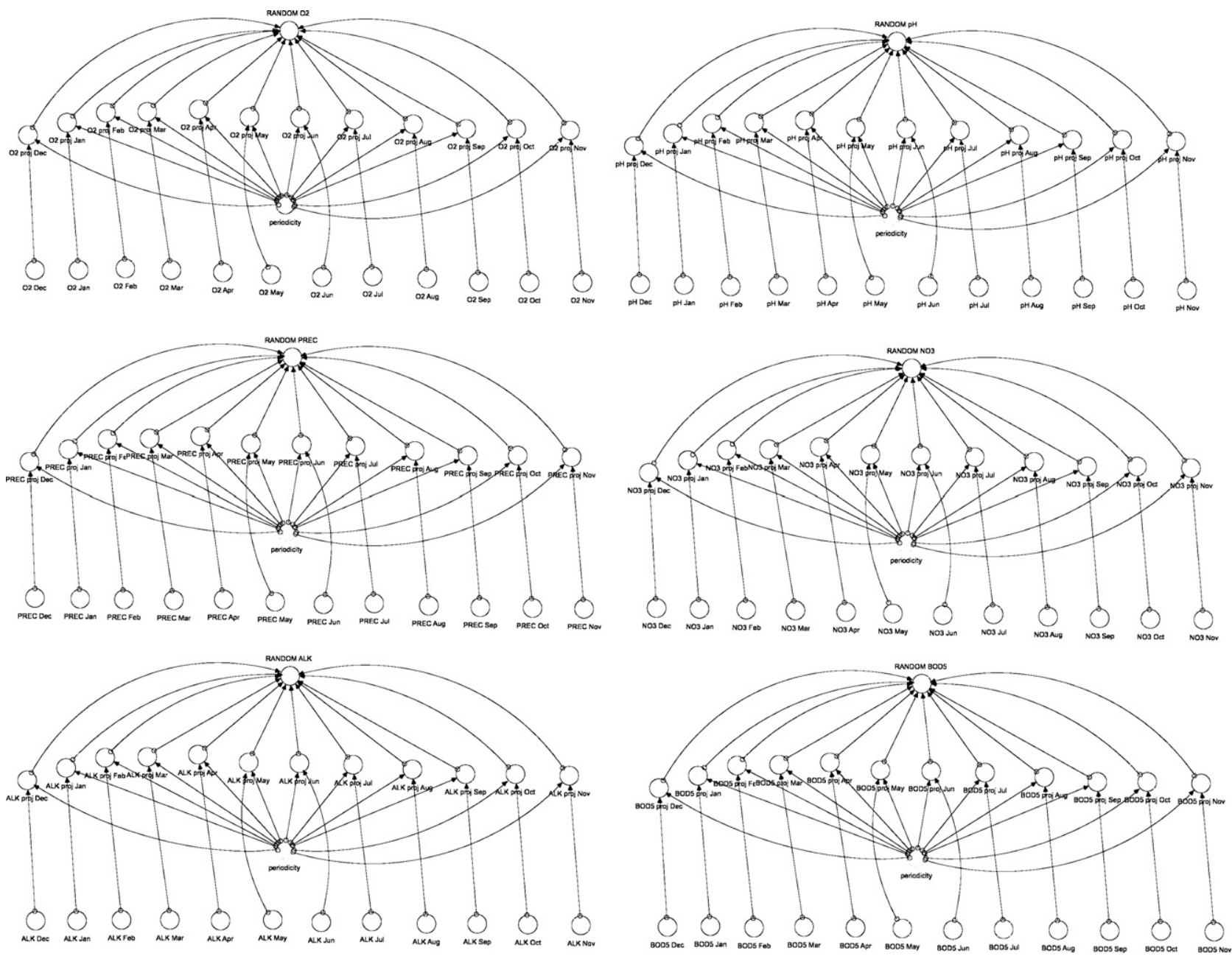

Fig. 3 - Conceptual diagram of the sub-model used to generate monthly stochastic calculations from the environmental data incorporated into the model.

Table 3 - Regression analysis (MODEL II) intercepts and slopes, and the respective 95\% confidence limits (in parenthesis), degrees of freedom (d.f.), coefficient of determination $\left(R^{2}\right), F$-values and significance level $\left(P<0.05 ;{ }^{* *} P<0.01 ;{ }^{* * *} P<0.001\right)$, for all the observed versus expected values of the biological metrics

\begin{tabular}{|c|c|c|c|c|c|c|}
\hline Metrics & Site & Intercept & Slope & d.f. & $R^{2}$ & $F$ \\
\hline \multirow[t]{3}{*}{ GTH and FILT } & P1 & $0.07(-2.23 ; 1.65)$ & $1.09(0.77 ; 1.55)$ & 11 & 0.794 & $42.33^{* * *+}$ \\
\hline & P2 & $0.19(-1.12 ; 1.27)$ & $0.98(0.81 ; 1.19)$ & 11 & 0.919 & $124.54^{* *+}$ \\
\hline & P3 & $-0.39(-2.28 ; 1.03)$ & $0.87(0.63 ; 1.19)$ & 11 & 0.819 & $49.61^{* * *}$ \\
\hline \multirow[t]{3}{*}{ PRD and PRS } & P1 & $-0.54(-2.35 ; 0.79)$ & $1.02(0.76 ; 1.38)$ & 11 & 0.837 & $56.67^{* * *}$ \\
\hline & P2 & $-0.99(1.35 ; 5.46)$ & $1.23(0.74 ; 2.15)$ & 11 & 0.637 & $19.89^{* * *}$ \\
\hline & P3 & $-0.14(-1.21 ; 0.73)$ & $1.10(0.92 ; 1.33)$ & 11 & 0.930 & $143.83^{*+*}$ \\
\hline \multirow[t]{3}{*}{ SRCP } & P1 & $-0.23(-0.94 ; 0.31)$ & $1.21(0.95 ; 1.55)$ & 11 & 0.882 & $82.61^{* * *}$ \\
\hline & P2 & $-0.04(-0.88 ; 0.79)$ & $0.85(0.58 ; 1.23)$ & 11 & 0.765 & $35.80^{* * * *}$ \\
\hline & P3 & $-0.22(-4.08 ; 0.89)$ & $1.31(0.17 ; 3.37)$ & 11 & 0.589 & $5.84^{*}$ \\
\hline \multirow[t]{3}{*}{ SHRD } & P1 & $-0.92(-1.88 ;-0.16)$ & $1.49(1.27 ; 1.79)$ & 11 & 0.938 & $167.66^{+\cdots+}$ \\
\hline & P2 & $-0.59(-2.09 ; 0.31)$ & $1.19(0.78 ; 1.87)$ & 11 & 0.845 & $27.55^{* *+}$ \\
\hline & P3 & $-0.34(-0.65 ;-0.12)$ & $2.38(1.95 ; 2.99)$ & 11 & 0.953 & 108.14 \\
\hline
\end{tabular}

P1, P2 and P3 represent the three sampling stations of the Pinhão river. The specification of all variables codes is expressed in Table 1. 


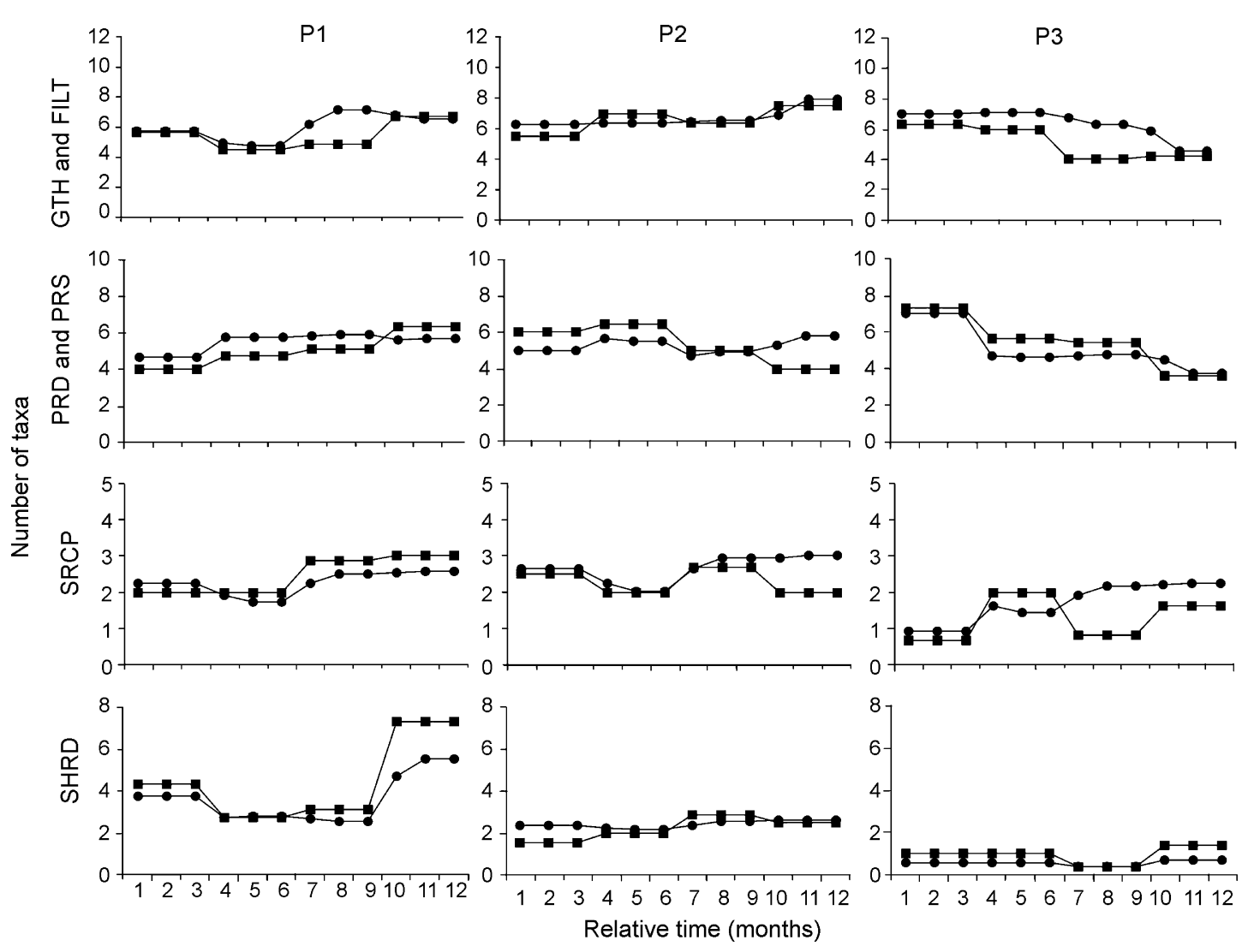

Fig. 4 - Graphical comparisons between simulated (black circles) and observed (black squares) values of the trophic metrics. The specification of all variable codes is expressed in Table 1. P1, P2 and P3 are sampling stations of the Pinhão watershed.

from the Pinhão watershed sampling stations (P1, P2 and P3) (Table 3). All the simulations were statistically validated by the regression analysis (MODEL II) (Table 3). Fig. 4 illustrates the confrontation between simulated and real values for all the trophic metrics considered for validation purposes. For these metrics, the model simulations accurately predicted the real values for P1, P2 and P3, with the same general tendencies (Fig. 4 and Table 3). Since Cabecinha et al. (2004) already validated the simulations for Ephemeroptera, Plecoptera and Trichoptera, the model behaves as expected for the reference situation considered.

The average environmental data from all the studied watersheds was calculated following the Water Framework Directive 2000/60/EC altitudinal criterion (Table 4). After the validation procedures, StDM simulations were used to test the model's performance in the sampling station C6 (from the Corgo river), facing scenarios either: (1) of pollution increase due to the agricultural intensification; or (2) of farming activity abandonment becoming less pollutant as a non-point source. The effects of water quality changes on biological components of the ecosystem were assessed by stochasticdynamic calculations of EPT reactions through time (Fig. 5). The model simulations showed credible trends for this metric as a response to the new scenarios considered. In fact, the increase of organic perturbation (expressed by nitrate concentrations) induces a clear decline in the number of species of the EPT group (Fig. 5). Moreover, when changes in land uses was simulated, resulting from agriculture abandonment, the decrease of contaminants (such as the anomalous nutrient enrichment) seemed to allowed a recovery of EPT taxa as a response to more suitable environmental conditions (Fig. 5). The model simulation results corroborate numerous studies that successfully applied the EPT taxonomic metric on biomonitoring programs, namely because these orders generally represent the more organic pollution intolerant organisms present in rivers and streams (Barbour et al., 1996, 1999; Wallace et al., 1996; Growns et al., 1997; Oliveira and Cortes, 2005).

\section{Discussion}

The main objective of the StDM approach proposed is a mechanistic understanding of the running waters ecological functioning in the scope of the need for rapid, standardized and cost-saving assessment methodologies. Our approach includes the interaction between aquatic macroinvertebrates trophic and taxonomic metrics and environmental conditions, with holistic and ecological relevance, and reduces the number of pre-conceptions added to the model. Therefore, this study seems to represent a useful contribution to give a referential basis for the holistic assessment and monitoring of the 
Table 4 - Reference values of environmental variables (average \pm S.D.) from a "typical" mountain stream of Northeast Portugal using an altitudinal gradient criterion

\begin{tabular}{|c|c|c|c|c|}
\hline Environmental variables & Spring & Summer & Autumn & Winter \\
\hline \multicolumn{5}{|l|}{ Altitude typology } \\
\hline \multicolumn{5}{|l|}{$\operatorname{High}(>800 \mathrm{~m})$} \\
\hline $\operatorname{ALK}\left(\right.$ meq L L $\left.^{-1}\right)$ & $0.16 \pm 0.02$ & $0.14 \pm 0.07$ & $0.28 \pm 0.08$ & $0.18 \pm 0.03$ \\
\hline $\mathrm{BOD}_{5}\left(\mathrm{mg} \mathrm{O}_{2} \mathrm{~L}^{-1}\right)$ & $0.53 \pm 0.26$ & $0.60 \pm 0.35$ & $1.33 \pm 0.26$ & $1.62 \pm 0.34$ \\
\hline $\mathrm{CL}\left(\mathrm{meq} \mathrm{L} \mathrm{L}^{-1}\right)$ & $0.01 \pm 0.00$ & $3.67 \pm 1.87$ & $5.83 \pm 2.31$ & $5.38 \pm 2.08$ \\
\hline $\operatorname{COND}\left(\mu \mathrm{mhos} \mathrm{cm}^{-1}\right)$ & $40.22 \pm 17.64$ & $40.88 \pm 17.26$ & $67.63 \pm 29.91$ & $50.79 \pm 25.18$ \\
\hline $\mathrm{COD}\left(\mathrm{mg} \mathrm{O}_{2} \mathrm{~L}^{-1}\right)$ & $7.24 \pm 6.95$ & $7.56 \pm 7.27$ & $3.68 \pm 0.92$ & $4.48 \pm 4.24$ \\
\hline DSOURCE $(\mathrm{km})$ & $12.74 \pm 5.17$ & $12.74 \pm 5.17$ & $12.74 \pm 5.17$ & $12.74 \pm 5.17$ \\
\hline HARD $\left(\right.$ meq L $\left.^{-1}\right)$ & $0.50 \pm 0.28$ & $0.42 \pm 0.27$ & $0.43 \pm 0.26$ & $0.29 \pm 0.16$ \\
\hline $\mathrm{NO}_{3}\left(\mathrm{mg} \mathrm{N}-\mathrm{NO}_{3} \mathrm{~L}^{-1}\right)$ & $0.01 \pm 0.00$ & $0.01 \pm 0.02$ & $0.07 \pm 0.05$ & $0.17 \pm 0.14$ \\
\hline $\mathrm{O}_{2}\left(\mathrm{mgL}^{-1}\right)$ & $10.31 \pm 1.03$ & $9.98 \pm 1.05$ & $8.80 \pm 0.73$ & $9.68 \pm 1.28$ \\
\hline pH (pH unidades) & $5.97 \pm 0.25$ & $6.05 \pm 0.29$ & $6.45 \pm 0.44$ & $6.50 \pm 0.40$ \\
\hline PREC (mm) & $96.31 \pm 20.73$ & $30.58 \pm 5.67$ & $129.24 \pm 41.72$ & $176.32 \pm 46.57$ \\
\hline \multicolumn{5}{|l|}{ Mid-altitude (200-800 m) } \\
\hline $\operatorname{ALK}\left(\right.$ meq L $\left.^{-1}\right)$ & $0.17 \pm 0.02$ & $0.18 \pm 0.03$ & $0.25 \pm 0.00$ & $0.07 \pm 0.06$ \\
\hline $\mathrm{BOD}_{5}\left(\mathrm{mg} \mathrm{O}_{2} \mathrm{~L}^{-1}\right)$ & $0.92 \pm 0.16$ & $0.92 \pm 0.21$ & $0.93 \pm 0.31$ & $2.40 \pm 0.20$ \\
\hline $\mathrm{CL}\left(\right.$ meq $\left.\mathrm{L}^{-1}\right)$ & $0.01 \pm 0.00$ & $4.15 \pm 0.83$ & $7.13 \pm 0.93$ & $7.10 \pm 1.42$ \\
\hline $\operatorname{COND}\left(\mu \mathrm{mhos} \mathrm{cm}^{-1}\right)$ & $61.93 \pm 11.87$ & $61.73 \pm 11.66$ & $97.83 \pm 22.49$ & $81.83 \pm 18.91$ \\
\hline $\mathrm{COD}\left(\mathrm{mg} \mathrm{O}_{2} \mathrm{~L}^{-1}\right)$ & $6.94 \pm 1.27$ & $7.41 \pm 1.53$ & $8.04 \pm 5.10$ & $5.92 \pm 5.32$ \\
\hline DSOURCE (km) & $14.44 \pm 5.98$ & $14.44 \pm 5.98$ & $14.44 \pm 5.98$ & $14.44 \pm 5.98$ \\
\hline HARD $\left(\right.$ meq L $\left.^{-1}\right)$ & $0.22 \pm 0.09$ & $0.22 \pm 0.08$ & $0.36 \pm 0.15$ & $0.51 \pm 0.49$ \\
\hline $\mathrm{NO}_{3}\left(\mathrm{mg} \mathrm{N} \_\mathrm{NO}_{3} \mathrm{~L}^{-1}\right)$ & $0.01 \pm 0.00$ & $0.01 \pm 0.01$ & $0.12 \pm 0.02$ & $0.01 \pm 0.19$ \\
\hline $\mathrm{O}_{2}\left(\mathrm{mg} \mathrm{L}^{-1}\right)$ & $9.44 \pm 0.48$ & $9.07 \pm 0.12$ & $8.63 \pm 0.32$ & $11.40 \pm 0.26$ \\
\hline $\mathrm{pH}$ (pH unidades) & $6.64 \pm 0.22$ & $6.83 \pm 0.25$ & $6.74 \pm 0.44$ & $5.17 \pm 0.75$ \\
\hline PREC (mm) & $89.19 \pm 13.15$ & $24.95 \pm 3.91$ & $127.47 \pm 17.29$ & $165.32 \pm 18.78$ \\
\hline \multicolumn{5}{|l|}{ Lowland $(<200 \mathrm{~m})$} \\
\hline $\operatorname{ALK}\left(\right.$ meq L $\left.^{-1}\right)$ & $0.16 \pm 0.01$ & $0.15 \pm 0.04$ & $0.39 \pm 0.01$ & $0.18 \pm 0.04$ \\
\hline $\mathrm{BOD}_{5}\left(\mathrm{mg} \mathrm{O}_{2} \mathrm{~L}^{-1}\right)$ & $1.42 \pm 0.40$ & $1.59 \pm 0.51$ & $2.13 \pm 1.21$ & $2.33 \pm 1.08$ \\
\hline CL $\left(\right.$ meq L $\left.L^{-1}\right)$ & $0.01 \pm 0.00$ & $5.30 \pm 1.51$ & $16.18 \pm 7.27$ & $8.43 \pm 3.04$ \\
\hline $\operatorname{COND}\left(\mu \mathrm{mhos} \mathrm{cm}^{-1}\right)$ & $68.10 \pm 23.76$ & $68.60 \pm 23.79$ & $159.83 \pm 79.42$ & $74.63 \pm 31.96$ \\
\hline $\operatorname{COD}\left(\mathrm{mg} \mathrm{O}_{2} \mathrm{~L}^{-1}\right)$ & $10.82 \pm 3.51$ & $11.48 \pm 3.45$ & $8.17 \pm 5.71$ & $8.15 \pm 2.92$ \\
\hline DSOURCE (km) & $33.70 \pm 7.42$ & $33.70 \pm 7.42$ & $33.70 \pm 7.42$ & $33.70 \pm 7.42$ \\
\hline HARD $\left(\right.$ meq L $\left.{ }^{-1}\right)$ & $0.46 \pm 0.11$ & $0.41 \pm 0.09$ & $0.69 \pm 0.20$ & $0.50 \pm 0.14$ \\
\hline $\mathrm{NO}_{3}\left(\mathrm{mg} \mathrm{N} \_\mathrm{NO}_{3} \mathrm{~L}^{-1}\right)$ & $0.01 \pm 0.00$ & $0.20 \pm 0.08$ & $0.62 \pm 0.10$ & $0.28 \pm 0.06$ \\
\hline $\mathrm{O}_{2}\left(\mathrm{mgL}^{-1}\right)$ & $10.33 \pm 0.65$ & $9.73 \pm 0.40$ & $8.75 \pm 0.21$ & $11.45 \pm 0.40$ \\
\hline pH (pH unidades) & $6.66 \pm 0.10$ & $6.83 \pm 0.14$ & $6.98 \pm 0.21$ & $6.35 \pm 0.35$ \\
\hline PREC $(\mathrm{mm})$ & $69.24 \pm 20.19$ & $25.48 \pm 8.72$ & $106.59 \pm 59.6$ & $129.29 \pm 23.79$ \\
\hline
\end{tabular}

The specification of all variable codes is expressed in Table 1.

ecological status in changed stream ecosystems, from which management strategies can be designed to restore biological communities that have been damaged by human activities. In fact, after the validation process, the simulation results show that the selected indicators, as state variables, were not indifferent to the structural changes expected to occur in a "typical" mountain stream of Northeast Portugal. The simulation results reflect well the shift of the stream characteristics towards known and new expected conditions and the state variables are capable of responding with credibility to key changes, namely as a result of the detrimental effects on the water quality.

Although the trophic metrics approach has been an important catalyst for the development of other major paradigms of stream ecology, the functional feeding group concept has also some limitations. Assignment of individual organisms from stream samples to a functional feeding group requires identification of the organism at least to the family level, and more often to the genus level (Wright et al., 1995). This is a time consuming task. Moreover, food selection may vary even at the species level according to habitat or food availability. Thus, published functional group designations are not always reliable. In fact, several stream organisms are known to fall into more than one functional feeding group or may change between functional feeding groups during their development (Hershey and Lamberti, 1998). Despite these shortcomings, the functional feeding group concept serves as a useful starting point to evaluate consumer functions in a given stream and to compare these functions between streams (Wright et al., 1995; Hershey and Lamberti, 1998). Since other related attributes of the macroinvertebrate community structure (such as the EPT group used in the present work), diversity and abundance are also influenced by certain environmental conditions (Karr and Dudley, 1981; Norris et al., 1995; Richards et al., 1993; Roth et al., 1996; Townsend et al., 1997a,b; Lounaci et al., 2000; Li et al., 2001), the philosophy of the proposed StDM can be 

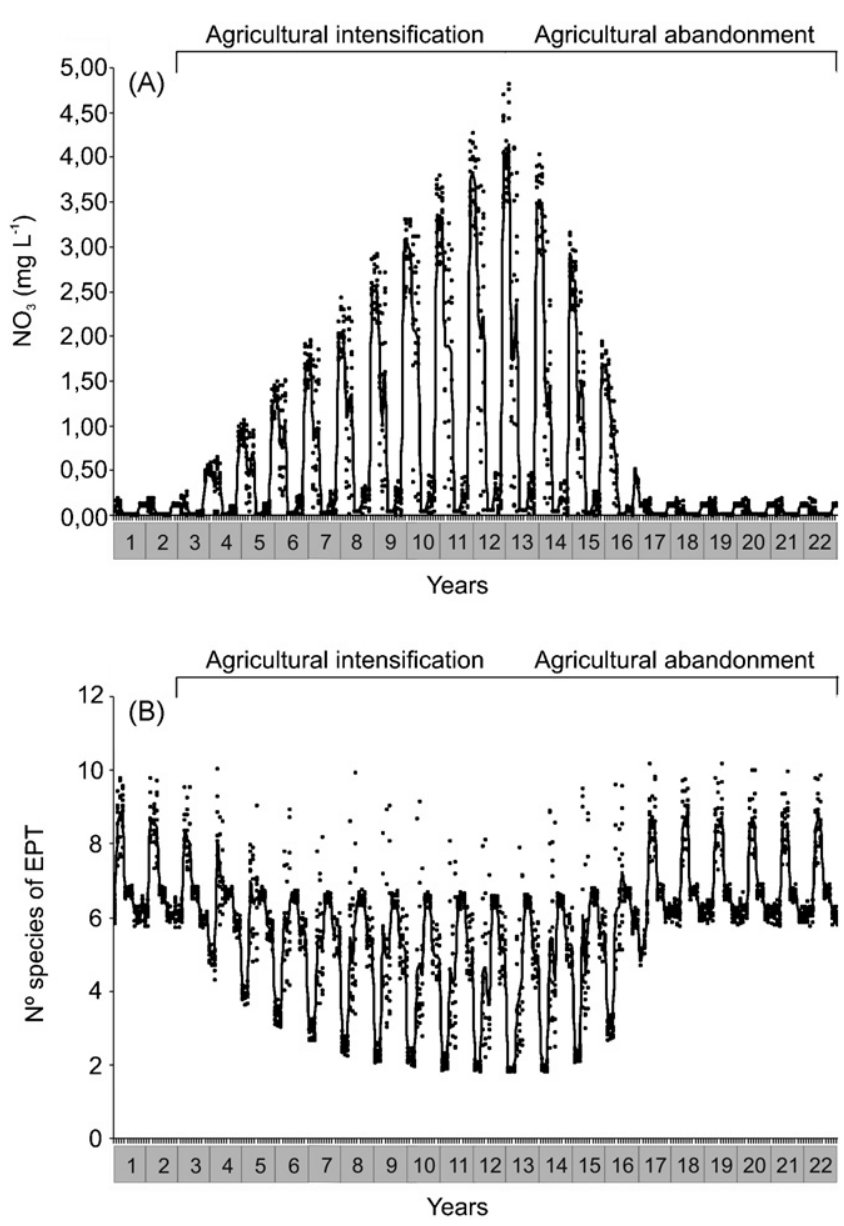

Fig. 5 - Computer simulations for the EPT metric estimated responses under the expected gradient of water quality changes (through a period of 22 years). (A) Nitrate concentrations and (B) number of species of EPT. The line connects the average values of monthly simulations for the sampling station $\mathrm{C6}$ of the Corgo watershed.

applicable generically to aquatic ecosystem management and policymaking, providing a useful contribution to define the reference conditions for surface water bodies from the quality elements specified in Annex V of the Water Framework Directive 2000/60/EC.

Nevertheless, the structure of such models should be straightforwardly interpretable in order to allow a decision maker to incorporate pertinent qualitative data before the model simulations (Parsons and Norris, 1996; Cabecinha et al., 2004). Džeroski et al. (1997) referred that models produced in the form of rules, based on machine learning approaches, are transparent and can be easily understood by experts. The StDM exhibits these structural qualities but provides also simple, suitable and intuitive outputs, easily interpreted by non-experts (ranging from resource users to senior policy makers). Although structurally simple, our StDM model captures the stochastic complexity of some holistic ecological trends, including true temporal and spatial gradients of stochastic environmental characteristics, which allowed the simulation of structural changes when habitat and environmental conditions are substantially changing due to anthropogenic-induced alterations.

When compared to other modelling methodologies for running water bodies, such as Artificial Intelligence (Walley and Džeroski, 1995; Džeroski et al., 1997, 2000; Walley et al., 1998; Walley and Fontama, 2000; Broekhoven et al., 2006), the StDM is more intuitive, namely in mathematical terms, providing easy explanations for the underlying relations between independent and dependent variables and because is based on conventional linear methods that allowed a more direct development of testable hypotheses (Manel et al., 1999).

Another goal when developing methods for assessing changes in the ecological integrity of ecosystems is the feasibility of application and extent to which the results can be applied in other contexts (Andreasen et al., 2001). In fact, the proposed methodology is expeditious and easily applicable to other type of biological metrics and aquatic ecosystems affected by gradients of changes (Cabecinha et al., 2004; SilvaSantos et al., 2006).

Overall, the main results showed that it is valid, interesting, and instructive to construct StDM models by focusing on the interactions between key-components of changing aquatic ecosystems. Nevertheless, since ecological integrity of the mountain streams can be only partly assessed by biological metrics occurrence, this approach also provides a useful starting point, allowing the precise development of more complicated models, with introduction of other indicators, interactions and interferences with precise applicability conditions. The ultimate goal is to produce simulation models that permit the creation of multi-patterns from changes in farming systems, whose patterns are the basis of spatially explicit ecological models (Costanza and Voinov, 2003). This approach will include not only the approach at the stream level but also the spatial configuration of the different kinds of natural and semi-natural habitats that concur in sustaining the entire ecological integrity of the studied watersheds. Therefore, we believe that our approach will provide the development of more global techniques in the scope of this research area by creating expeditious interfaces with Geographic Information Systems, which will make the methodology more instructive and credible to decision-makers and environmental managers (Costanza, 1992; Costanza and Voinov, 2003; Santos and Cabral, 2003).

\section{Acknowledgment}

This research was supported by the Foundation for Science and Technology (FCT), POCI Project (POCI/AND/56424/2004).

\section{Appendix A}

Mathematical equations used in Stella for the relationships between the trophic metrics and the environmental physicochemical variables from the studied watersheds. As an example, the environmental data of the sampling station P1 was used. The specification of all variable codes is expressed in Table 1. 


\section{Difference equations}

$\log E P H(t)=\log E P H(t-d t)+(E P H$ gains $-E P H$ losses $-E P H$ adjust $) \times d t$

$\log \operatorname{PLEC}(t)=\log \operatorname{PLEC}(t-d t)+($ PLEC gains - PLEC losses - PLEC adjust $) \times d t$

$\log$ TRIC $(t)=\log$ TRIC $(t-d t)+($ TRIC gains - TRIC losses - TRIC adjust $) \times d t$

$\log$ GTH and FILT $(t)=\log$ GTH and FILT $(t-d t)+($ GTH and FILT gains - GTH and FILT losses - GTH and FILT adjust $) \times d t$ $\log P R D$ and $P R S(t)=\log P R D$ and PRS $(t-d t)+(P R D$ and PRS gains - PRD and PRS losses - PRD and PRS adjust $) \times d t$ $\log \operatorname{SHRD}(t)=\log \operatorname{SHRD}(t-d t)+($ SRHD gains - SRHD losses - SRHD adjust $) \times d t$

$\log \operatorname{SRCP}(t)=\log \mathrm{SRCP}(\mathrm{t}-\mathrm{dt})+(\mathrm{SRCP}$ gains $-\mathrm{SRCP}$ losses $-\mathrm{SRCP}$ adjust $) \times d t$

Process equations

(a) $\log \mathrm{EPH}$

Initial richness of $\log \mathrm{EPH}=0$

$\mathrm{EPH}$ gains $=1.805+0.255 \times \log \mathrm{DSOURCE}$

$\mathrm{EPH}$ losses $=1.718 \times \log \mathrm{pH}+0.831 \times \log \mathrm{NO}_{3}$

$\mathrm{EPH}$ adjust $=\log \mathrm{EPH}$

(b) $\log$ PLEC

Initial richness of $\log P L E C=0$

PLEC gains $=0.145 \times \log$ PREC $+0.457 \times \log$ ALT $+0.256 \times \log$ DSOURCE

PLEC losses $=1.385$

PLEC adjust $=\log$ PLEC

(c) $\log$ TRIC

Initial richness of $\log$ TRIC $=0$

TRIC gains $=0.305 \times \log \mathrm{BOD}_{5}+0.274 \times \log \mathrm{ALT}$

TRIC losses $=0.300+0.822 \times \log \mathrm{NO}_{3}$

TRIC adjust $=\log$ TRIC

(d) GTH and FILT

Initial richness of $\log$ GTH and FILT $=0$

GTH and FILT gains $=0.783+0.317 \times \log \mathrm{BOD}_{5}$

GTH and FILT losses $=0.774 \times \log \mathrm{NO}_{3}$

GTH and FILT adjust $=\log$ GTH and FILT

(e) PRD and PRS

Initial richness of $\log \mathrm{PRD}$ and $\mathrm{PRS}=0$

$\mathrm{PRD}$ and $\mathrm{PRS}$ gains $=2.042+1.469 \times \log \mathrm{ALK}$

$\mathrm{PRD}$ and PRS losses $=1.528 \times \log \mathrm{pH}+0.862 \times \log \mathrm{NO}_{3}$

$\mathrm{PRD}$ and $\mathrm{PRS}$ adjust $=\log \mathrm{PRD}$ and $\mathrm{PRS}$

(f) SHRD

Initial richness of $\log \mathrm{SHRD}=0$

SRHD gains $=0.950 \times \log \mathrm{O}_{2}+1.359 \times \log \mathrm{ALK}+0.526 \times \log \mathrm{ALT}$

SRHD losses $=1.978$

SRHD adjust $=\log$ SHRD

(g) SRCP

Initial richness of $\log \mathrm{SRCP}=0$

$\mathrm{SRCP}$ gains $=0.147 \times \log \mathrm{PREC}+0.256 \times \log \mathrm{ALT}+0.266 \times \log \mathrm{DSOURCE}$

SRCP losses $=0.744$

SRCP adjust $=\log$ SRCP

Associated variables

$\mathrm{CHIR}=10^{\wedge}(\log \mathrm{CHIR})-1$

$\mathrm{EPH}=10 \hat{0}(\log \mathrm{EPH})-1$

$\log \mathrm{ALT}=\log _{10}(\mathrm{ALT}+1)$

$\log \mathrm{BOD}_{5}=\log _{10}\left(\mathrm{BOD}_{5}+1\right)$

$\log \mathrm{COND}=\log _{10}(\mathrm{COND}+1)$

$\log$ DSOURCE $=\log _{10}($ DSOURCE + 1)

$\log$ HARD $=\log _{10}($ HARD + 1)

$\log \mathrm{NO}_{3}=\log 10\left(\mathrm{NO}_{3}\right.$ Final +1$)$

$\log \mathrm{pH}=\log _{10}(\mathrm{pH}+1)$

$\log$ PREC $=\log _{10}($ PREC +1$)$ 


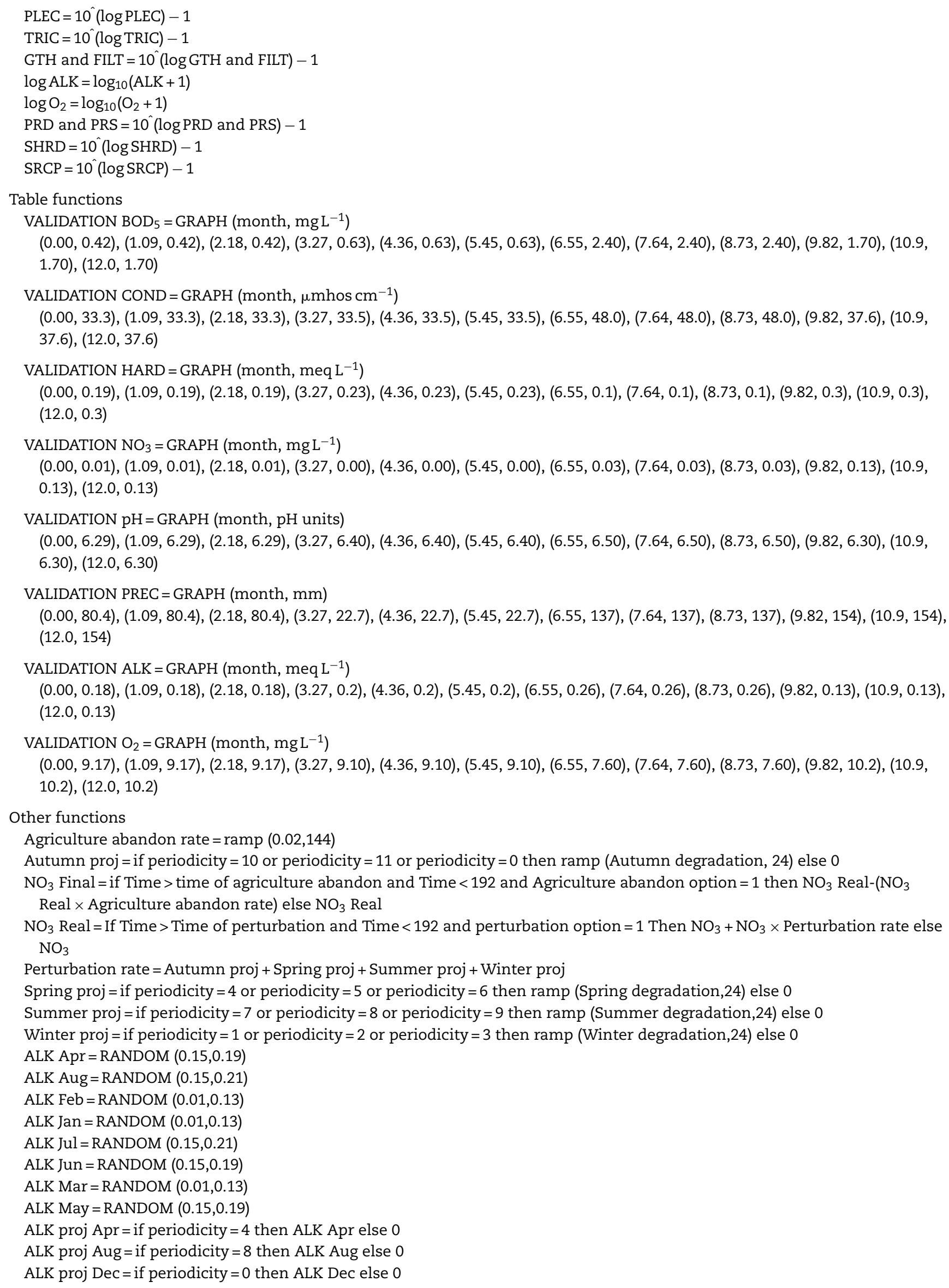


ALK proj Feb $=$ if periodicity $=2$ then ALK Feb else 0 ALK proj Jan $=$ if periodicity $=1$ then ALK Jan else 0 ALK proj Jul $=$ if periodicity $=7$ then ALK Jul else 0 ALK proj Jun $=$ if periodicity $=6$ then ALK Jun else 0 ALK proj Mar $=$ if periodicity $=3$ then ALK Mar else 0 ALK proj May $=$ if periodicity $=5$ then ALK May else 0 ALK proj Nov $=$ if periodicity $=11$ then ALK Nov else 0 ALK proj Oct $=$ if periodicity $=10$ then ALK Oct else 0 ALK proj Sep $=$ if periodicity $=9$ then ALK Sep else 0 ALK Sep = RANDOM $(0.15,0.21)$

$\mathrm{BOD}_{5} \mathrm{Apr}=\mathrm{RANDOM}(0.76,1.08)$

$\mathrm{BOD}_{5}$ Aug = RANDOM $(0.71,1.13)$

$\mathrm{BOD}_{5}$ Dec $=$ RANDOM $(0.62,1.24)$

$\mathrm{BOD}_{5} \mathrm{Feb}=\mathrm{RANDOM}(2.2,2.6)$

$\mathrm{BOD}_{5}$ Jan $=$ RANDOM $(2.2,2.6)$

$\mathrm{BOD}_{5} \mathrm{Jul}=\mathrm{RANDOM}(0.71,1.13)$

$\mathrm{BOD}_{5}$ Jun $=$ RANDOM $(0.76,1.08)$

$\mathrm{BOD}_{5} \mathrm{Mar}=\mathrm{RANDOM}(2.2,2.6)$

$\mathrm{BOD}_{5}$ May $=$ RANDOM $(0.76,1.08)$

$\mathrm{BOD}_{5}$ Nov $=$ RANDOM $(0.62,1.24)$

$\mathrm{BOD}_{5}$ Oct $=$ RANDOM $(0.62,1.24)$

$\mathrm{BOD}_{5}$ proj $\mathrm{Apr}=$ if periodicity $=4$ then $\mathrm{BOD}_{5}$ Apr else 0 $\mathrm{BOD}_{5}$ proj $\mathrm{Aug}=$ if periodicity $=8$ then $\mathrm{BOD}_{5}$ Aug else 0 $\mathrm{BOD}_{5}$ proj $\mathrm{Dec}=$ if periodicity $=0$ then $\mathrm{BOD}_{5}$ Dec else 0 $\mathrm{BOD}_{5}$ proj $\mathrm{Feb}=$ if periodicity $=2$ then $\mathrm{BOD}_{5}$ Feb else 0 $\mathrm{BOD}_{5}$ proj Jan $=$ if periodicity $=1$ then $\mathrm{BOD}_{5}$ Jan else 0 $\mathrm{BOD}_{5}$ proj Jul $=$ if periodicity $=7$ then $\mathrm{BOD}_{5}$ Jul else 0 $\mathrm{BOD}_{5}$ proj Jun $=$ if periodicity $=6$ then $\mathrm{BOD}_{5}$ Jun else 0 $\mathrm{BOD}_{5}$ proj $\mathrm{Mar}=$ if periodicity $=3$ then $\mathrm{BOD}_{5}$ Mar else 0 $\mathrm{BOD}_{5}$ proj May $=$ if periodicity $=5$ then $\mathrm{BOD}_{5}$ May else 0 $\mathrm{BOD}_{5}$ proj Nov $=$ if periodicity $=11$ then $\mathrm{BOD}_{5}$ Nov else 0 $\mathrm{BOD}_{5}$ proj Oct $=$ if periodicity $=10$ then $\mathrm{BOD}_{5}$ Oct else 0 $\mathrm{BOD}_{5}$ proj Sep $=$ if periodicity $=9$ then $\mathrm{BOD}_{5}$ Sep else 0 $\mathrm{BOD}_{5}$ Sep $=$ RANDOM $(0.71,1.13)$

COND Apr $=$ RANDOM $(50.06,73.8)$

COND Aug $=$ RANDOM $(50.07,73.39)$

COND Dec $=$ RANDOM $(75.34,120.32)$

COND Feb $=$ RANDOM $(62.92,100.74)$

COND Jan $=$ RANDOM $(62.92,100.74)$

COND Jul = RANDOM $(50.07,73.39)$

COND Jun $=$ RANDOM $(50.06,73.8)$

COND Mar $=$ RANDOM $(62.92,100.74)$

COND May $=$ RANDOM $(50.06,73.8)$

COND Nov $=$ RANDOM $(75.34,120.32)$

COND Oct $=$ RANDOM $(75.34,120.32)$

COND proj Apr $=$ if periodicity $=4$ then COND Apr else 0 COND proj Aug $=$ if periodicity $=8$ then COND Aug else 0 COND proj Dec $=$ if periodicity $=0$ then COND Dec else 0 COND proj Feb $=$ if periodicity $=2$ then COND Feb else 0 COND proj Jan $=$ if periodicity $=1$ then COND Jan else 0 COND proj Jul $=$ if periodicity $=7$ then COND Jul else 0 COND proj Jun $=$ if periodicity $=6$ then COND Jun else 0 COND proj Mar $=$ if periodicity $=3$ then COND Mar else 0 COND proj May $=$ if periodicity $=5$ then COND May else 0 COND proj Nov $=$ if periodicity $=11$ then COND Nov else 0 COND proj Oct $=$ if periodicity $=10$ then COND Oct else 0 COND proj Sep $=$ if periodicity $=9$ then COND Sep else 0 COND Sep $=$ RANDOM $(50.07,73.39)$

HARD Apr $=$ RANDOM $(0.13,0.31)$ 
HARD Aug $=$ RANDOM $(0.14,0.30)$
HARD Dec $=\operatorname{RANDOM}(0.21,0.51)$
HARD Feb $=\operatorname{RANDOM}(0.02,1)$
HARD Jan $=\operatorname{RANDOM}(0.02,1)$
HARD Jul $=$ RANDOM $(0.14,0.30)$
HARD Jun $=$ RANDOM $(0.13,0.31)$
HARD Mar $=$ RANDOM $(0.02,1)$
HARD May $=\operatorname{RANDOM}(0.13,0.31)$
HARD Nov $=$ RANDOM $(0.21,0.51)$
HARD Oct $=$ RANDOM $(0.21,0.51)$

HARD proj Apr $=$ if periodicity $=4$ then HARD Apr else 0 HARD proj Aug $=$ if periodicity $=8$ then HARD Aug else 0 HARD proj Dec $=$ if periodicity $=0$ then HARD Dec else 0 HARD proj Feb $=$ if periodicity $=2$ then $\mathrm{HARD}$ Feb else 0 HARD proj Jan $=$ if periodicity $=1$ then HARD Jan else 0 HARD proj Jul $=$ if periodicity $=7$ then HARD Jul else 0 HARD proj Jun $=$ if periodicity $=6$ then HARD Jun else 0 HARD proj Mar $=$ if periodicity $=3$ then HARD Mar else 0 HARD proj May $=$ if periodicity $=5$ then HARD May else 0 HARD proj Nov $=$ if periodicity $=11$ then HARD Nov else 0 HARD proj Oct $=$ if periodicity $=10$ then HARD Oct else 0 HARD proj Sep $=$ if periodicity $=9$ then HARD Sep else 0 HARD Sep = RANDOM $(0.14,0.30)$

$\mathrm{NO}_{3} \mathrm{Aug}=\mathrm{RANDOM}(0,0.02)$

$\mathrm{NO}_{3}$ Dec $=$ RANDOM $(0.10,0.14)$

$\mathrm{NO}_{3} \mathrm{Feb}=\operatorname{RANDOM}(0,0.2)$

$\mathrm{NO}_{3} \mathrm{Jan}=\operatorname{RANDOM}(0,0.2)$

$\mathrm{NO}_{3} \mathrm{Jul}=\mathrm{RANDOM}(0,0.02)$

$\mathrm{NO}_{3} \mathrm{Mar}=\operatorname{RANDOM}(0,0.2)$

$\mathrm{NO}_{3} \mathrm{Nov}=\operatorname{RANDOM}(0.10,0.14)$

$\mathrm{NO}_{3}$ Oct $=\mathrm{RANDOM}(0.10,0.14)$

$\mathrm{NO}_{3}$ proj Apr $=$ if periodicity $=4$ then $\mathrm{NO}_{3}$ Apr else 0 $\mathrm{NO}_{3}$ proj Aug $=$ if periodicity $=8$ then $\mathrm{NO}_{3}$ Aug else 0 $\mathrm{NO}_{3}$ proj Dec $=$ if periodicity $=0$ then $\mathrm{NO}_{3}$ Dec else 0 $\mathrm{NO}_{3}$ proj Feb $=$ if periodicity $=2$ then $\mathrm{NO}_{3}$ Feb else 0 $\mathrm{NO}_{3}$ proj Jan $=$ if periodicity $=1$ then $\mathrm{NO}_{3}$ Jan else 0 $\mathrm{NO}_{3}$ proj Jul = if periodicity $=7$ then $\mathrm{NO}_{3}$ Jul else 0 $\mathrm{NO}_{3}$ proj Jun $=$ if periodicity $=6$ then $\mathrm{NO}_{3}$ Jun else 0 $\mathrm{NO}_{3}$ proj $\mathrm{Mar}=$ if periodicity $=3$ then $\mathrm{NO}_{3}$ Mar else 0 $\mathrm{NO}_{3}$ proj May $=$ if periodicity $=5$ then $\mathrm{NO}_{3}$ May else 0 $\mathrm{NO}_{3}$ proj Nov $=$ if periodicity $=11$ then $\mathrm{NO}_{3}$ Nov else 0 $\mathrm{NO}_{3}$ proj Oct $=$ if periodicity $=10$ then $\mathrm{NO}_{3}$ Oct else 0 $\mathrm{NO}_{3}$ proj Sep $=$ if periodicity $=9$ then $\mathrm{NO}_{3}$ Sep else 0 $\mathrm{NO}_{3}$ Sep $=$ RANDOM $(0,0.02)$

$\mathrm{O}_{2}$ Apr $=\mathrm{RANDOM}(8.96,9.92)$

$\mathrm{O}_{2}$ Aug $=\mathrm{RANDOM}(8.95,9.19)$

$\mathrm{O}_{2}$ Dec $=$ RANDOM $(8.31,8.95)$

$\mathrm{O}_{2} \mathrm{Feb}=\mathrm{RANDOM}(11.14,11.66)$

$\mathrm{O}_{2}$ Jan $=$ RANDOM $(11.14,11.66)$

$\mathrm{O}_{2} \mathrm{Jul}=\mathrm{RANDOM}(8.95,9.19)$

$\mathrm{O}_{2}$ Jun $=\mathrm{RANDOM}(8.96,9.92)$

$\mathrm{O}_{2} \mathrm{Mar}=\mathrm{RANDOM}(11.14,11.66)$

$\mathrm{O}_{2}$ May $=\operatorname{RANDOM}(8.96,9.92)$

$\mathrm{O}_{2} \mathrm{Nov}=\mathrm{RANDOM}(8.31,8.95)$

$\mathrm{O}_{2}$ Oct $=$ RANDOM $(8.31,8.95)$

$\mathrm{O}_{2}$ proj Apr $=$ if periodicity $=4$ then $\mathrm{O}_{2}$ Apr else 0 $\mathrm{O}_{2}$ proj Aug $=$ if periodicity $=8$ then $\mathrm{O}_{2}$ Aug else 0 $\mathrm{O}_{2}$ proj Dec $=$ if periodicity $=0$ then $\mathrm{O}_{2}$ Dec else 0 $\mathrm{O}_{2}$ proj $\mathrm{Feb}=$ if periodicity $=2$ then $\mathrm{O}_{2}$ Feb else 0 
$\mathrm{O}_{2}$ proj Jan $=$ if periodicity $=1$ then $\mathrm{O}_{2}$ Jan else 0

$\mathrm{O}_{2}$ proj Jul $=$ if periodicity $=7$ then $\mathrm{O}_{2}$ Jul else 0

$\mathrm{O}_{2}$ proj Jun $=$ if periodicity $=6$ then $\mathrm{O}_{2}$ Jun else 0

$\mathrm{O}_{2}$ proj Mar $=$ if periodicity $=3$ then $\mathrm{O}_{2}$ Mar else 0

$\mathrm{O}_{2}$ proj May $=$ if periodicity $=5$ then $\mathrm{O}_{2}$ May else 0

$\mathrm{O}_{2}$ proj Nov $=$ if periodicity $=11$ then $\mathrm{O}_{2}$ Nov else 0

$\mathrm{O}_{2}$ proj Oct $=$ if periodicity $=10$ then $\mathrm{O}_{2}$ Oct else 0

$\mathrm{O}_{2}$ proj Sep $=$ if periodicity $=9$ then $\mathrm{O}_{2}$ Sep else 0

$\mathrm{O}_{2}$ Sep $=$ RANDOM $(8.95,9.19)$

Periodicity $=$ time $-12 \times$ int $($ time/12)

$\mathrm{pH}$ Apr $=$ RANDOM $(6.42,6.86)$

$\mathrm{pH}$ Aug $=$ RANDOM $(6.58,7.08)$

$\mathrm{pH}$ Dec $=\operatorname{RANDOM}(6.3,7.18)$

$\mathrm{pH} F \mathrm{Feb}=\mathrm{RANDOM}(4.42,5.92)$

$\mathrm{pH}$ Jan $=$ RANDOM $(4.42,5.92)$

$\mathrm{pH}$ Jul = RANDOM $(6.58,7.08)$

$\mathrm{pH}$ Jun = RANDOM $(6.42,6.86)$

$\mathrm{pH}$ Mar = RANDOM $(4.42,5.92)$

$\mathrm{pH}$ May $=\mathrm{RANDOM}(6.42,6.86)$

$\mathrm{pH}$ Nov $=$ RANDOM $(6.3,7.18)$

$\mathrm{pH}$ Oct $=$ RANDOM $(6.3,7.18)$

$\mathrm{pH}$ proj $\mathrm{Apr}=$ if periodicity $=4$ then $\mathrm{pH}$ Apr else 0

$\mathrm{pH}$ proj $\mathrm{Aug}=$ if periodicity $=8$ then $\mathrm{pH}$ Aug else 0

$\mathrm{pH}$ proj $\mathrm{Dec}=$ if periodicity $=0$ then $\mathrm{pH}$ Dec else 0

$\mathrm{pH}$ proj Feb $=$ if periodicity $=2$ then $\mathrm{pH}$ Feb else 0

$\mathrm{pH}$ proj Jan $=$ if periodicity $=1$ then $\mathrm{pH}$ Jan else 0

$\mathrm{pH}$ proj Jul $=$ if periodicity $=7$ then $\mathrm{pH}$ Jul else 0

$\mathrm{pH}$ proj Jun $=$ if periodicity $=6$ then $\mathrm{pH}$ Jun else 0

$\mathrm{pH}$ proj Mar $=$ if periodicity $=3$ then $\mathrm{pH}$ Mar else 0

$\mathrm{pH}$ proj May $=$ if periodicity $=5$ then $\mathrm{pH}$ May else 0

$\mathrm{pH}$ proj $\mathrm{Nov}=$ if periodicity $=11$ then $\mathrm{pH}$ Nov else 0

$\mathrm{pH}$ proj Oct $=$ if periodicity $=10$ then $\mathrm{pH}$ Oct else 0

$\mathrm{pH}$ proj Sep $=$ if periodicity $=9$ then $\mathrm{pH}$ Sep else 0

$\mathrm{pH}$ Sep $=$ RANDOM $(6.58,7.08)$

PREC Apr $=$ RANDOM $(76.04,102.34)$

PREC Aug $=$ RANDOM $(21.04,28.86)$

PREC Dec $=$ RANDOM $(110.18,144.76)$

PREC Feb $=$ RANDOM $(146.54,184.1)$

PREC Jan $=$ RANDOM $(146.54,184.1)$

PREC Jul = RANDOM $(21.04,28.86)$

PREC Jun $=$ RANDOM $(76.04,102.34)$

PREC Mar = RANDOM $(146.54,184.1)$

PREC May $=$ RANDOM $(76.04,102.34)$

PREC Nov $=$ RANDOM $(110.18,144.76)$

PREC Oct $=$ RANDOM $(110.18,144.76)$

PREC proj Apr $=$ if periodicity $=4$ then PREC Apr else 0 PREC proj Aug $=$ if periodicity $=8$ then PREC Aug else 0 PREC proj Dec $=$ if periodicity $=0$ then PREC Dec else 0 PREC proj Feb $=$ if periodicity $=2$ then PREC Feb else 0 PREC proj Jan $=$ if periodicity $=1$ then PREC Jan else 0 PREC proj Jul $=$ if periodicity $=7$ then PREC Jul else 0 PREC proj Jun $=$ if periodicity $=6$ then PREC Jun else 0 PREC proj Mar $=$ if periodicity $=3$ then PREC Mar else 0 PREC proj May $=$ if periodicity $=5$ then PREC May else 0 PREC proj Nov $=$ if periodicity $=11$ then PREC Nov else 0 PREC proj Oct $=$ if periodicity $=10$ then PREC Oct else 0 PREC proj Sep $=$ if periodicity $=9$ then PREC Sep else 0 PREC Sep = RANDOM(21.04,28.86)

$\mathrm{BOD}_{5}=$ if Stochastic $\mathrm{ON}$ OFF $=1$ then RANDOM BOD else VALIDATION BOD $_{5}$ 
COND $=$ if Stochastic ON OFF $=1$ then RANDOM COND else VALIDATION COND

HARD $=$ if Stochastic ON OFF $=1$ then RANDOM HARD else VALIDATION HARD

$\mathrm{NO}_{3}=$ if Stochastic ON OFF $=1$ then RANDOM NO${ }_{3}$ else VALIDATION NO

$\mathrm{pH}=$ if Stochastic ON OFF $=1$ then RANDOM pH else VALIDATION $\mathrm{pH}$

$\mathrm{PREC}=$ if Stochastic $\mathrm{ON}$ OFF $=1$ then RANDOM PREC else VALIDATION PREC

ALK $=$ if Stochastic ON OFF $=1$ then RANDOM ALK else VALIDATION ALK

$\mathrm{O}_{2}=$ if Stochastic $\mathrm{ON}$ OFF $=1$ then $\mathrm{RANDOM} \mathrm{O} \mathrm{O}_{2}$ else VALIDATION $\mathrm{O}_{2}$

Composed variables

RANDOM ALK = ALK proj Dec + ALK proj Jan + ALK proj Feb + ALK proj Mar + ALK proj Apr + ALK proj May + ALK proj Jun + ALK proj Jul + ALK proj Aug + ALK proj Sep + ALK proj Oct + ALK proj Nov

RANDOM BOD $5=\mathrm{BOD}_{5}$ proj Dec $+\mathrm{BOD}_{5}$ proj Jan $+\mathrm{BOD}_{5}$ proj Feb $+\mathrm{BOD}_{5}$ proj $\mathrm{Mar}+\mathrm{BOD}_{5}$ proj $\mathrm{Apr}+\mathrm{BOD}_{5}$ proj $\mathrm{May}+\mathrm{BOD}_{5}$ proj $\mathrm{Jun}+\mathrm{BOD}_{5}$ proj Jul $+\mathrm{BOD}_{5}$ proj Aug $+\mathrm{BOD}_{5}$ proj $\mathrm{Sep}+\mathrm{BOD}_{5}$ proj Oct $+\mathrm{BOD}_{5}$ proj Nov

RANDOM COND = COND proj Dec + COND proj Jan + COND proj Feb + COND proj Mar + COND proj Apr + COND proj May + COND proj Jun + COND proj Jul + COND proj Aug + COND proj Sep + COND proj Oct + COND proj Nov

RANDOM HARD = HARD proj Dec + HARD proj Jan + HARD proj Feb + HARD proj Mar + HARD proj Apr + HARD proj May + HARD proj Jun + HARD proj Jul + HARD proj Aug + HARD proj Sep + HARD proj Oct + HARD proj Nov

RANDOM NO$N_{3}=\mathrm{NO}_{3}$ proj Dec $+\mathrm{NO}_{3}$ proj Jan $+\mathrm{NO}_{3}$ proj Feb $+\mathrm{NO}_{3}$ proj $\mathrm{Mar}+\mathrm{NO}_{3}$ proj Apr $+\mathrm{NO}_{3}$ proj $\mathrm{May}+\mathrm{NO}_{3}$ proj Jun $+\mathrm{NO}_{3}$ proj Jul $+\mathrm{NO}_{3}$ proj Aug $+\mathrm{NO}_{3}$ proj Sep $+\mathrm{NO}_{3}$ proj Oct $+\mathrm{NO}_{3}$ proj $\mathrm{Nov}$

$\mathrm{RANDOM} \mathrm{O} \mathrm{O}_{2}=\mathrm{O}_{2}$ proj Dec $+\mathrm{O}_{2}$ proj Jan $+\mathrm{O}_{2}$ proj Feb $+\mathrm{O}_{2}$ proj Mar $+\mathrm{O}_{2}$ proj Apr $+\mathrm{O}_{2}$ proj May $+\mathrm{O}_{2}$ proj Jun $+\mathrm{O}_{2}$ proj Jul $+\mathrm{O}_{2}$ proj Aug $+\mathrm{O}_{2}$ proj Sep $+\mathrm{O}_{2}$ proj Oct $+\mathrm{O}_{2}$ proj Nov

RANDOM pH $=$ pH proj Dec + pH proj Jan + pH proj Feb + pH proj Mar + pH proj Apr + pH proj May + pH proj Jun + pH proj Jul + pH proj Aug + pH proj Sep + pH proj Oct + pH proj Nov

RANDOM PREC = PREC proj Dec + PREC proj Jan + PREC proj Feb + PREC proj Mar + PREC proj Apr + PREC proj May + PREC proj Jun + PREC proj Jul + PREC proj Aug + PREC proj Sep + PREC proj Oct + PREC proj Nov

$\mathrm{EPT}=\mathrm{EPH}+\mathrm{PLEC}+\mathrm{TRIC}$

Constants

Agriculture abandon option $=1$

ALT $=690$

Autumn degradation $=0.279$

DSOURCE $=7.5$

perturbation option $=1$

Spring degradation $=0.043$

Summer degradation $=0.235$

Stochastic ON OFF $=1$

time of agriculture abandon $=144$

Time of perturbation $=24$

Winter degradation $=0.174$

ALK Dec $=0.25$

ALK Nov $=0.25$

ALK Oct $=0.25$

$\mathrm{NO}_{3} \mathrm{Apr}=0.01$

$\mathrm{NO}_{3}$ Jun $=0.01$

$\mathrm{NO}_{3} \mathrm{May}=0.01$

\section{R E F E R E N C E S}

Alba-Tercedor, J., Sánchez-Ortega, A., 1998. Un método rápido y simple para avalorar la calidad biológica de las aguas corrientes basado en el Hellawell (1978). Limnetica 4, 5156.

Andreasen, J.K., O’Neill, R.V., Noss, R., Slosser, N.C., 2001. Considerations for the development of a terrestrial index of ecological integrity. Ecol. Indicators 1, 21-25.
Angermeier, P.L., Karr, J.R., 1994. Biological integrity versus biological diversity as policy directives: protecting biotic resources. BioSience 44, 690-697.

Ault, J.S., Luo, J., Smith, S.G., Serafy, J.E., Wang, J.D., Humston, R., Diaz, G.A., 1999. A spatial dynamic multistock production model. Can. J. Fisheries Aquat. Sci. 56 (1), 4-25.

Barbour, M.T., Gerritsen, J., Griffith, G.E., Frydenborg, R., McCarron, E., White, J.S., Bastian, M.L., 1996. A framework for biological criteria for Florida streams using benthic macroinvertebrates. J. North Am. Benthol. Soc. 15, 185-211. 
Barbour, M.T., Gerritsen, J., Snyder, B.D., Stribling, J.B., 1999. Rapid Bioassessment Protocols for Use in Streams and Wadeable Rivers: Periphyton, Benthic Macroinvertebrates and Fish, second edition. EPA. U.S. Environmental Protection Agency, Office of Water, Washington, D.C.

Broekhoven, E., Adriaenssens, V., Baets, B., Verdonschot, P., 2006. Fuzzy rule-based macroinvertebrate habitat suitability models for running waters. Ecol. Modell. 198 (1-2), 71-84.

Brosse, S., Lek, S., Townsend, C.R., 2001. Abundance, diversity, and structure of freshwater invertebrates and fish communities: an artificial neural network approach. New Zealand J. Marine Freshwater Res. 35, 135-145.

Cabecinha, E., Cortes, R., Cabral, J.A., 2004. Performance of a stochastic-dynamic modelling methodology for running waters ecological assessment. Ecol. Modell. 175, 303-317.

Cabral, J.A., Marques, J.C., Nielsen, S.N., 2001. Modeling mosquitofish (Gambusia holbrooki) responses to Genapol OXD-080, a non-ionic surfactant, in rice fields. Ecol. Eng. 16, 537-544.

Cabral, J.A., Rocha, A., Santos, M., Crespí, A.L., 2007. A stochastic dynamic methodology (SDM) to facilitate handling simple passerine indicators in the scope of the agri-environmental measures problematics. Ecol. Indicators 7, 34-47.

Charvet, S., Statzner, B., Useglio-Polatera, P., Dumont, B., 2000. Traits of benthic macroinvertebrates in semi-natural French streams: an initial application to biomonitoring in Europe. Freshwater Biol. 43, 277-296.

Cortes, R.M.V., 1992. Seasonal pattern of benthic communities along the longitudinal axis of river systems and the influence of abiotic factors on the spatial structure of those communities. Arch. Hydrobiol. 126, 85-103.

Cortes, R.M.V., Oliveira, S.V., Cabral, D.A., Santos, S., Ferreira, T., 2002. Different scales of analysis in classifying streams: from a multimetric towards an integrate system approach. River Res. Appl. 18 (4), 367-382.

Costanza, R., 1992. Towards an operational definition of ecosystem health. In: Costanza, R., Norton, B., Haskell, B. (Eds.), Ecosystem Health: New Goals for Environmental Management. Island Press, Washington, DC, pp. 239256.

Costanza, R., Voinov, A., 2001. Modelling ecological and economic systems with STELLA: part III. Ecol. Modell. 143 (1-2), 1-7.

Costanza, R., Voinov, A., 2003. Introduction: spatially explicit landscape simulation models. In: Costanza, R., Voinov, A. (Eds.), Landscape Simulation Modeling, A Spatially Explicit, Dynamic Approach. Springer-Verlag, New York, pp. 3-20.

Dale, V.H., Beyeler, S.C., 2001. Challenges in the development and use of ecological indicators. Ecol. Indicators 1, 3-10.

Doisy, K.E., Rabeni, C.F., 2001. Flow conditions, benthic food resources, and invertebrate community composition in a low-gradient stream in Missouri. J. North Am. Benthol. Soc. 20 (1), 17-32.

Dolèdec, S., Statner, B., Bournaud, M., 1999. Species traits for future biomonitoring across ecoregions: patterns along a human-impacted river. Freshwater Biol. 42, 737-758.

Džeroski, S., Grbovic, J., Walley, W.J., Kompare, B., 1997. Using machine learning techniques in the construction of models. 2, Data analysis with rule induction. Ecol. Modell. 95 (1), 95-111.

Džeroski, S., Demšar, D., Grbovic, J., 2000. Predicting chemical parameters of river water quality from bioindicator data. Appl. Intelligence 13, 7-17.

Growns, J.E., Chessman, B.C., Jackson, J.E., Ross, D.G., 1997. Rapid assessment of Australian rivers using macroinvertebrates: cost and efficiency of 6 methods of sample processing. J. North Am. Benthol. Soc. 16, 682-693.

Harris, J.H., Silveira, R., 1999. Large-scale assessments of river health using an index of biotic integrity with low-diversity fish communities. Freshwater Biol. 41, 235-252.
Hershey, A.E., Lamberti, G.A., 1998. Stream macroinvertebrate communities. In: Naimam, R.J., Bilby, R.E. (Eds.), River Ecology and Management-Lessons From the Pacific Coastal Ecoregion. Springer-Verlag, New York, pp. 169-199.

Jørgensen, S.E., 2001. Fundamentals of Ecological Modelling, third ed. Elsevier, Amsterdam, p. 630.

Jørgensen, S.E., Bernardi, R., 1997. The application of a model with dynamic structure to simulate the effect of mass fish mortality on zooplankton structure in Lago de Annone. Hidrobiologia 356, 87-96.

Karouby, O., Iliadis, A., Durbecb, J., Riandeyb, V., Carlotti, F., 2007. Stochastic modelling for determining zooplankton abundance. Ecol. Model. 204, 372-378.

Karr, J.R., 1999. Defining and measuring river health. Freshwater Biol. 41, 221-234.

Karr, J.R., 2002. What from ecology is relevant to design and planning? In: Johnson, B.R., Hill, K. (Eds.), Ecology and Design: Frameworks for Learning. Island Press, Washington, D.C., pp. 133-172.

Karr, J.R., Chu, E.W., 2001. Sustaining living rivers. Hydrobiology 422/423, 1-14.

Karr, J.R., Dudley, D.R., 1981. Ecological perspective on water quality goals. J. Environ. Manage. 5 (1), 55-68.

Karr, J.R., Rossano, E.M., 2001. Applying public health lessons to protect river health. Ecol. Civil Eng. 4, 3-18.

Kay, W.R., Smith, M.J., Pinder, A.M., McRae, J.M., Davies, J.A., Halse, S.A., 1999. Patterns of distribution of macroinvertebrate families in rivers of north-western Australia. Freshwater Biol. 41, 299-316.

Kimberling, D.N., Karr, J.R., Fore, L., 2001. Measuring human disturbance using terrestrial invertebrates in shrub-stepp of eastern Washington (USA). Ecol. Indicators 1, 63-81.

Kurtz, J.C., Jackson, L.E., William, S.F., 2001. Strategies for evaluating indicators based on guidelines from the Environmental Protection Agency's Office of Research and Development. Ecol. Indicators 1, 49-60.

Lenat, D.R., 1988. Water quality assessment of streams using a qualitative collection method for benthic macroinvertebrates. J. North Am. Benthol. Soc. 7, 222-233.

Li, J., Herlihy, A., Gerth, W., Kaufmann, P., Gregory, S., Urquhart, S., Larsen, D.P., 2001. Variability in stream macroinvertebrates at multiple spatial scales. Freshwater Biol. 46, 87-97.

Lounaci, A., Brosse, S., Thomas, A., Lek, S., 2000. Abundance, diversity and community structure of macroinvertebrates in an Algerian stream: the Sébaou wadi. Annals Limnol. 36, 123-133.

Manel, S., Dias, J., Ormerod, S.J., 1999. Comparing discriminant analysis, neural networks and logistic regression for predicting species distributions: a case study with a Himalayan river bird. Ecol. Modell. 120 (2-3), 337-347.

Marchant, R., Hirst, A., Norris, R., Metzeling, L., 1999. Classification of macroinvertebrate communities across drainage basins in Victoria, Australia: consequences of sampling on a broad spatial scale for predictive modelling. Freshwater Biol. 41, 253-268.

Maxted, J.R., Barbour, M.T., Gerritsen, J., Poretti, Primrose, N., Silvia, A., Penrose, D., Renfrow, R., 2000. Assessment framework for mid Atlantic coastal plain streams using benthic macroinvertebrates. J. North Am. Benthol. Soc. 19 (1), 128-144.

Mitsch, W.J., Jørgensen, S.E., 1989. Introduction to ecological engineering. In: Mitsch, W.J., Jørgensen, S.E. (Eds.), Ecological Engineering. John Wiley and Sons, New York, pp. 3-12.

Moss, D., Wrigth, J.F., Furse, M.T., Clarke, R.T., 1999. A comparison of alternative techniques for prediction of the fauna of running-water sites in Great Britain. Freshwater Biol. 41, 167-181. 
Norris, R.H., Hart, B.T., Finlayson, M., Norris, K.R., 1995. Use of the biota to access water quality. Aust. J. Ecol. 20, 1-27.

Oberdorf, T., Pont, D., Hugheny, B., Chessel, D., 2001. A probabilistic model characterizing fish assemblages of french rivers: a framework for environmental assessment. Freshwater Biol. 46, 399-415.

Oliveira, S.V., Cortes, R.M.V., 2005. A biological relevant habitat condition index for streams in northern Portugal. Aquatic Conserv.: Marine Freshwater Ecosyst. 15, 189-210.

Pardal, M.A., Cardoso, P.G., Sousa, J.P., Marques, J.C., Raffaelli, D., 2004. Assessing environmental quality: a novel approach. Marine Ecol. Prog. Ser. 267, 1-8.

Parsons, M., Norris, R.H., 1996. The effect of habitat specific sampling on biological assessment of water quality using a predictive model. Freshwater Biol. 36, 419-434.

Pauw, N.E., Vanhooren, G., 1983. Method for biologic quality assessment of watercourses in Belgium. Hydrobiologia 100, 153-168.

Rabeni, C.F., 2000. Evaluating physical habitat integrity in relation to the biological potential of streams. Hydrobiologia 422/423, 245-256.

Richards, C., Host, G.E., Arthur, J.W., 1993. Identification of predominant environmental factors structuring stream macroinvertebrate communities within a large agricultural catchment. Freshwater Biol. 29, 285-294.

Roth, N.E., Allan, J.D., Erickson, D.E., 1996. Landscape influences on stream biotic integrity assay at multiple spatial scales. Landscape Ecol. 11, 141-156.

Sampaio, A.C.R., 1995. Evaluation of a Mini-Hidric Impact in a Lotic Ecosystem: In a Particular Case of Terragido in Corgo River. M.Sc. Thesis. University of Trás-os-Montes e Alto Douro, Vila Real.

Santos, M., Cabral, J.A., 2003. Development of a stochastic dynamic model for ecological indicators prediction in changed Mediterranean agroecosytems of north-eastern Portugal. Ecol. Indicators 3, 285-303.

Seager, J., 1999. Perspectives and limitations of indicators in water management. J. Aquat. Ecosyst. Health 21, 44-48.

Silva-Santos, P., Pardal, M.A., Lopes, R.J., Murias, T., Cabral, J.A., 2006. A stochastic dynamic methodology (SDM) to the modelling of trophic interactions, with a focus on estuarine eutrophication scenarios. Ecol. Indicators 6, 394-408.

Smith, M.J., Kay, W.R., Edward, D.H.D., Papas, P.J., Richardson, St.J., Simpson, J.C., Pinder, A.M., Cale, D.J., Horwitz, P.H.J., Davis, J.A., Yung, F.H., Norris, R.H., Halse, S.A., 1999. AusRivAS: using macroinvertebrates to assess ecological condition of rivers in Western Australia. Freshwater Biol. 41, 269-282.

Sokal, R.R., Rohlf, F.J., 1995. Biometry, third ed. W.H. Freeman and Company, New York.

Thorne, R.St.J., Williams, W.P., 1997. The response of benthic invertebrates to pollution in developing countries: a multimetric system of bioassessment. Freshwater Biol. 37, 671-686.
Townsend, C.R., Riley, R.H., 1999. Assessment of river health: accounting for perturbation pathways in physical and ecological space. Freshwater Biol. 41, 393-405.

Townsend, C.R., Dolédec, S., Scarsbrook, M.R., 1997a. Species traits in relation to temporal and spatial heterogeneity in streams: a test of habitat template theory. Freshwater Biol. 37, 367-387.

Townsend, C.R., Arbuckle, C.J., Crowl, T.A., Scarsbrook, M.R., 1997b. The relationship between land use and physicochemistry, food resources and macroinvertebrate communities in tributaries of the Taieri River, New Zealand: a hierarchically scaled approach. Freshwater Biol. 37, 177-191.

Turak, E., Flack, L.K., Norris, R.H., Simpson, J., Waddell, N., 1999. Assessment of river condition at a large spatial scale using predictive models. Freshwater Biol. 41, 283-298.

Van der Meer, J., Duin, R.N.M., Meininger, P.L., 1996. Statistical analysis of long-term monthly Oystercatcher Haematopus ostralegus counts. Ardea 84A, 39-55.

Voinov, A., Voinov, H., Constanza, R., 2001. Surface water flow in landscape models: 2 Patuxent watershed case study. Ecol. Modell. 119, 211-230.

Wallace, W.J., Grubaugh, J.W., Whiles, M.R., 1996. Biotic indices and stream ecosystem processes: results from an experimental study. Ecol. Appl. 6, 140-151.

Walley, W.J., Džeroski S., 1995. Biological monitoring: a comparison between Bayesian, neural and machine learning methods of water quality classification. In: Denzer, R., Schimak, G., Russell, D. (Eds.), Proceedings of the International Symposium on Environmental Software Systems, IFIP Conference Series. Chapman \& Hall, London.

Walley, W.J., Fontama, V.N., Martin, R.W., 1998. Applications of Artificial Intelligence in River Quality Surveys. R\&D Technical Report E52, Environment Agency, Bristol.

Walley, W.J., Fontama, V.N., 2000. New approaches to river quality classification based upon artificial intelligence. In: Furse, M.T., Wright, J.F. (Eds.), Assessing the Biological Quality of Fresh Waters: RIVPACS and Other Techniques. Freshwater Biological Association, Ambleside, UK.

Whiles, M.R., Brock, B.L., Franzen, A.C., Dinsmore, S.C., 2000. Stream invertebrate communities, water quality, and land-use patterns in an agricultural drainage basin of Northeastern Nebraska, USA. J. Environ. Manage. 26 (5), 563-576.

Wright, J.F., 1995. Development and use of a system for predicting the macroinvertebrate fauna in flowing waters. Aust. J. Ecol. 20, 181-197.

Wright, I.A., Chessman, B.C., Fairweather, P.G., Benson, L.J., 1995. Measuring the impact of sewage effluent on the macroinvertebrate community of an upland stream: the effect of different levels of taxonomic resolution and quantification. Aust. J. Ecol. 20, 142-149.

Zar, J.H., 1996. Biostatistical Analysis, third ed. Prentice-Hall International Inc., Englewood Cliffs, New Jersey. 